University of Rhode Island

DigitalCommons@URI

Open Access Master's Theses

1979

\title{
A COMPARISON OF SOLUBILIZED AND MEMBRANE BOUND FORMS OF CHOLINE-O-ACETYLTRANSFERASE IN MOUSE BRAIN NERVE ENDINGS
}

Craig Paul Smith

University of Rhode Island

\section{Recommended Citation}

Smith, Craig Paul, "A COMPARISON OF SOLUBILIZED AND MEMBRANE BOUND FORMS OF CHOLINE-OACETYLTRANSFERASE IN MOUSE BRAIN NERVE ENDINGS" (1979). Open Access Master's Theses. Paper 226.

https://digitalcommons.uri.edu/theses/226

This Thesis is brought to you for free and open access by DigitalCommons@URI. It has been accepted for inclusion in Open Access Master's Theses by an authorized administrator of DigitalCommons@URI. For more information, please contact digitalcommons-group@uri.edu. 
A COMPARISON OF SOLUBILIZED AND MEMBRANE BOUND FORMS OF CHOLINE-O-ACETYLTRANSFERASE IN MOUSE BRAIN NERVE ENDINGS

BY

CRAIG PAUL SMITH

A THESIS SUBMITTED IN PARTIAL FULFILLMENT OF THE REQUIREMENTS FOR THE DEGREE OF

MASTER OF SCIENCE

IN

PHARMACOLOGY

UNIVERSITY OF RHODE ISLAND

1979 
MASTER OF SCIENCE THESIS

OF

CRAIG PAUL SMITH

Approved:

Thesis Committee

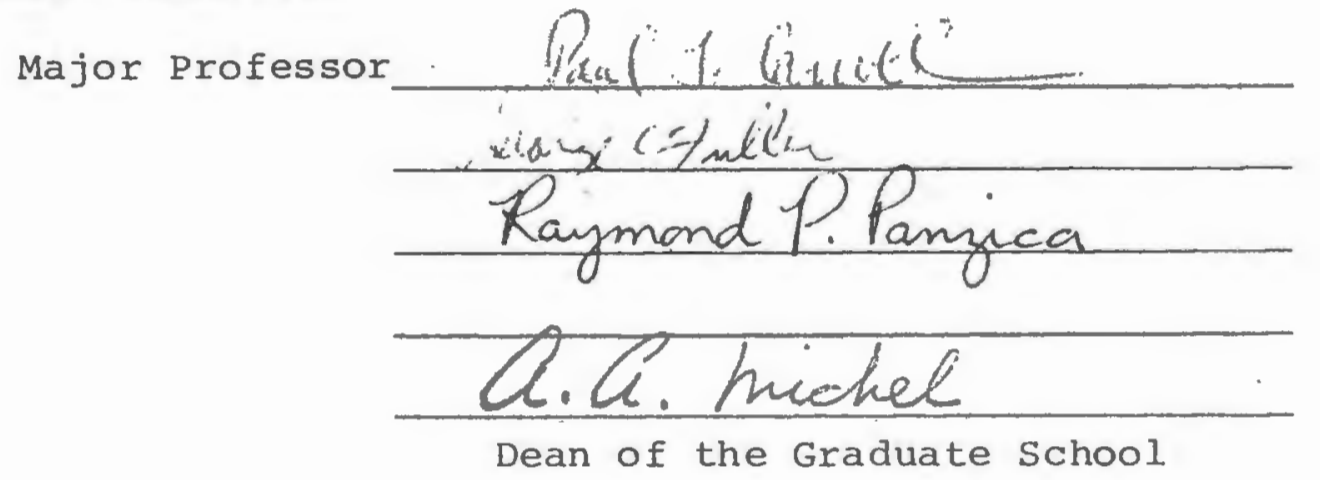

UNIVERSITY OF RHODE ISLAND

1979 


\section{ABSTRACT}

Mouse brain choline-O-acetyltransferase (E.C. 2.3.1.6) (ChAT) activity was studied in vitro using a lo0mM sodium phosphate buffer ( $\mathrm{pH} 7.4$ ) wash of a crude vesicular fraction containing solubilized ChAT and a. washed crude vesicular fraction containing membrane bound ChAT. Both the solubilized, and membrane bound forms of ChAT can acetylate choline linearly for 30 minutes. High concentrations of acetylcholine (Ach) can inhibit solubilized ChAT to a greater degree than the membrane bound enzyme form. Forty percent of the Ach synthesized by membrane bound ChAT survives hydrolysis in the presence of an excess of acetylcholinesterase (AchE), whereas none of the Ach synthesized by the solubilized enzyme form does. 4-(1-naphthylvinyl)pyridine inhibits solubilized ChAT more than the membrane bound form, either in vivo or in vitro, and reduces mouse locomotor activity by $80-90 \%$, for 3 hours. Solubilized ChAT is totally sodium dependent whereas the membrane bound form is only partially sodium dependent. Membrane bound ChAT has both a high (Km 3.2 uM) and a low affinity $(\mathrm{Km}=0.48 \mathrm{mM})$ Michaelis constants as a function of added choline when velocity values are not corrected for acetylation of endogenous choline. Upon correction, only a low affinity Michaelis constant $(\mathrm{Km}=0.47 \mathrm{mM})$ is obtained for the membrane 
bound enzyme form, similar to that of solubilized ChAT $(\mathrm{Km}=.17 \mathrm{mM})$. The choline analogues triethylcholine and homocholine are acetylated preferentially by membrane bound ChAT. The results suggest the existence of a membrane bound form of ChAT in mouse brain which is able to synthesize Ach. 
I would like to thank and acknowledge my family, especially my mother and father, and my aunt and cousin, Gary, who provided me with love and support.

I would like to thank and acknowledge my major professor for his direction and guidance, and stephen Nelson for his friendship and understanding.

I would like to thank all my friends in and out of the Department of Pharmacology and Girolamo ortolano and Kathy Valeo, and Brett and Keith.

I would like to acknowledge the Department of Pharmacology for financial support.

I would like to dedicate this thesis to the memory of my grandmother. 
To my Mother, Father, Aunt, and Cousin 
TABLE OF CONTENTS

Page

INTRODUCTION. . . . . . . . . . . . . . . . . . . 1

LITERATURE REVIEW •. . . . . . . . . . . . . 6

The Mechanism of Solubilized ChAT . . . . . . . 10

Inhibition of ChAT. . . . . . . . . . . . 15

Choline.................. . . 17

Choline Analogues . . . . . . . . . . . . 21

Acetyl COA and Analogues. . . . . . . . . 25

Regulation of ChAT. . . . . . . . . . . . . 27

Quantal Theory and Vesicle Hypothesis . . . . 30

Pools of Ach. . . . . . . . . . . . . . 31

Free Ach . . . . . . . . . . . . . . : 31

Bound Ach: Cytoplasmic and Vesicular. . . . . 32

Localization of ChAT. . . . . . . . . . : . 33

Classical Hypothesis. . . . . . . . . . . . 33

Fine STructure of the Presynaptic Nerve Terminal. $\quad 36$

MATERIALS AND METHODS . . . . . . . . . . . . . 40

Preparation of Mouse Brain Choline-O-Acetyl-

transferase ................ . . 4 40

Assay for ChAT Activity . . . . . . . . . . 42

Descending Paper Chromatography . . . . . . . . 43

Inhibition Studies. . . . . . . . . . . . . 44

Locomotor Activity Measurements . . . . . . . . 44

Choline Analogue Synthesis:. . . . . . . . . 45

Analysis of Enzyme Kinetics . . . . . . . . 45

Statistics. . . . . . . . . . . . . . 46

Limitations of this study :. . . . . . . . . 46

Materials . . . . . . . . . . . . . . 4 46

RESULTS • • . . . • . . . . . . . . . . 47

DISCUSSION. • • • • . . . . • • . . . . 56

TABLES. . . . . . . . . . . . . . . 63

FIGURES . . . . . . . . . . . . . . . 72

REFERENCES. . . . . . . . . . . . . . . . . 79 
TABLE

PAGE

1 The Recovery and Distribution of Synaptosomal Choline-O-Acetyltransferase (ChAT) and Protein

2 Inhibition of Solubilized and Membrane Bound Choline-O-Acetyltransferase (ChAT) by Acetylcholine (ACh)... . . . . . . . . . .

3 Determination of Choline-O-Acetyltransferase (ChAT) Activity in Subcellular Fractions of Mouse Forebrain in the Presence and Absence of Excess Acetylcholinesterase (AchE). . . .

4 The Effect of Lowered Socium Ion Concentration on Choline-o-Acetyltransferase (ChAT) in Subcellular Fractions of Mouse Brain. . . .

5 In vitro Inhibition of Solubilized and Membrane Bound Forms of Choline-o-Acetyltransferase (ChAT) by 4-(1-nephthylvinyl) pyridine (4-NVP) . . . . . . . . . . .

6 In vivo Inhibition of Solubilized and Membrane Bound Forms of Choline-O-Acetyltransferase (ChAT) by 4-(1-naphthylvinlyl) pyridine (4-NVP) ...............

7 Reported $\mathrm{K}_{\mathrm{m}}$ Values for Brain Choline-0-Acetyltransferase (ChAT), expressed in micromolar. .

8 Comparison of Membrane Bound Enzyme Activities in the Presence of Various Choline Concentrations . . . . . .............

9 Apparent $R_{f}$ Value of the Acetylated Products obtained by Paper Chromatography with

Various Substrates from Mouse Brain Mince. . . 


\section{LIST OF FIGURES}

FIGURE

PAGE

1 Subcellular Fractionation and Enzyme Preparation. . . . . . . . . . . . . . . .

2 Acetylation of Choline by Membrane Bound and Solubilized Forms of ChAT ( $\square$ and , respectively) over time . . . . . . . .

3 Effect of 4-(1-naphthylvinyl) pyridine (4-NVP) on Mouse Locomotor Activity . . .

4 Choline Kinetics of the Membrane Bound Enzyme Form, corrected (-) and uncorrected (--) for endogenous acetylation. . . . . .

5 Choline Kinetics of the Solubilized Enzyme Form, corrected (-) and uncorrected (---), for Endogenous Acetylation. . . . . . .

6 Acetylation of Exogenous Triethylcholine (TEC) (日) Homocholine ( $m$ ), and Endogenous Substrate (ㅁ) over time by Membrane Bound ChAT . . . . . . . . . . . . . .

7 Acetylation of Exogenous Triethylcholine (TEC) ( $\mathrm{FA})$, Homocholine ( $m$ ), and Endogenous substrate (口) over time by solubilized ChAT . . . . . . . . . . . . . 
INTRODUCTION

Acetylcholine is a putative transmitter in the central nervous system, and is beleived to be stored in two subcellular pools in the central cholinergic nerve ending, the cytoplasm and the synaptic vesicles (DeRobertis et al, 1963; Whittaker et al, 1964; see review by Hebb, 1972). The majoroty of the enzyme which synthesizes acetylcholine(Ach) from choline and acetyl CoA, choline-o-acetyltransferase (E.C.2.3.1.6.) (ChAT) is beleived to exist freely in the cytoplasm of the nerve ending under physiological conditions (Fonnum, 1966; 1967; 1968; 1973; 1975). The Ach stored in synaptic vesicles is beleived to originate in the cytoplasm (Foningm;973; 1975t. In the classical model of central cholinergic neurotransmission, Ach is synthesized in the cytoplasm and transferred to vesicles, where it is released during depolarization. However, the transfer of cytoplasmic Achinto vesicles (Marchbanks, 1968; Katz et.al, 1973; Carroll and Nelson, 1978) or synaptic vesicle ghosts @Suszkiw, 1976) above diffusion levels has not been demonstrated. Recently, it has been reported that some ChAT is associated with synaptic vesicles (Fattori et al, 1976; Feigenson and Barrnett, 1977), although the relative physiological roles of the enzyme in this location and that present in the cytoplasm remain to be established.

Several investigators have suggested that a form of ChAT may be associated with the presynaptic neuronal membrane (Guyenet et al, 1973; Barker and Mittag, 1975; Faubrich and 
Chippendale, 1977), and may be responsible for the efficient acetylation of choline accumulated by the high affinity choline transport system, whish is beleived to be associated with cholinergic nerve endings, in contrast to the low affinity choline transport process (Kuhar et al, 1973; 1975). The high affinity transport process has a $\mathrm{K}_{t}$ value for choline in the micromolar range (Yamamura and Synder, 1972; 1973; Barker and Mittag, 1975; Carroll and Buterbaugh, 1975a; 1975b; Carroll and Gol berg, 1975) and consequently, ChAT may be associated with membranes and have a lower $\mathrm{K}_{\mathrm{m}}$ for choline than solubilized, or cytoplasmic, ChAT, the most widely studied form of the enzyme, which has been reported to have $\mathrm{K}_{\mathrm{m}}$ values for choline in the millimolar range (see Table 1). Furthermore, evidence concerning the substrate specificity of ChAT indicates that a form of ChAT exists in nerve endings which is able to efficiently acetylate homocholine, a choline analogue which is not acetylated by the solubilized form of ChAT (Burgen et al, 1956; Dauterman and Mehrotra, 1963; Currier and Maunter, 1974; Collier et al, 1977), even at micromolar concentrations (Collier et al, 1977). One group of investigators has reported that 4-(1-naphthylvinyl)pyridine (4-NVP), a potent in vitro inhibitor of solubilłzed ChAT (Smith et al, 1967; Allen et al, 1970; CavalIito et al, 1970; Baker and Gibson, 1971; 1972; Goldberg et al, 1971; Krell and Golmberg, 1975) is only able to maximally inhibit nerve ending ChAT in vivo by $65 \%$ without affecting intracellular Ach levels (Krell and Goldberg, 1975). 
One possible explanation for these results is that ChATiis in excess in the nerve ending (Schuberth et al, 1970; Carsmn et al, 1972; Ross et al, 1971; Hebb, 1972; Glick et al, 1973; Saelens et al, 1973; Jenden et al, 1974; Krell and Goldberg, 1975). An Excess of ChAT in the nerve ending could account for choline acetylation from high affinity choline transport concentrations and a 65\% nerve ending ChAT inhibition without an affect on Ach levels. It should be noted that nerve ending ChAT was inhibited by $65 \%$ at dosage levels of either 200 or $400 \mathrm{mg} / \mathrm{kg} 4-\mathrm{NVP}$. Since complete inhibition of nerve enging ChAT by 4-NVP could not be reached, and the choline analogue homocholine could be acetylated by intact synaptosomes but not the solubilized preparation of nerve nding ChAT, other possible explanations may be that other forms of ChAT are present in vivo which are not inhibited by 4-NVP and are able to mamtain brain Ach levels, and are also less substrate specific thansolubilized ChAT, as has been suggested by Collier et al (1977), or that compartments exist in the nerve ending which are not identically exposed to the inhibitor or choline analogues and enough ChAT is expsxses either protected from 4-NVP inhibition to maintain intracellular Ach levels, or enough ChAT is exposed to choline analogues to allow acetylation. The existence of such compartments has been suggested by studies of nerve endings and synaptosomes employing non-osmicating fixation techniques which have revealed a membranous presynaptic network (Bloom and Aghajanien, 1966; Jones, 1969; 1970) and a presynaptic vesicular grid (Jones, 1972). 
The purpose of this research was to determine if a nonsoluble or membrane bound form of ChAT exists in mouse brain nerve endings, and to compare some of its properti es with those of the solubilized enzyme form.

The enzyme forms used in this study ere prepared from minces offforebrain of male (CF-1) albino mice, which were incubated in a $35 \mathrm{mMK}^{+} \mathrm{Krebs}$ bicarbonate buffer medium (pH7.4). This incubation procedure is beleived to simulate physiological stimulation (Salehmoghaddam and Collier, 1976; Carroll and Goldberg, 1976) and reduce intracellular Ach levels, which maybe inhibitory to the synthesis of Ach (Kaita and Goldberg, 1969; Glover and Potter, 1971; Farris et al, 1978). Subcellular fractions were prepared according to the method of Gray and Whittaker (1962), as modified by Collier et al (1972) and Salehnoghaddam and Collier (1976). The stnaptosomal fraction was hypo-osmotically shooled by an approximate 10 fold excess of glass distilled water ( $\mathrm{pH} 4.0$ ), and high ionic strength washes (100mM sodium phosphate buffer, $\mathrm{pH}$ 7.4, ionic strength 160mi ) of the crude vesicular fraction, obtained after high speed centrifugation, solubilized that ChAT ionically bound to membranes (Fonnum,1966; 1967; 1968; 1975) Hebb, 1972). The washed crude vesicular fraction, containing nonionically membrane bound ChAT, was then suspended in a three fold excess of glass distilled water ( $\mathrm{pH} 4.0$ ). The enzyme activities were determined using the buffer substrate described by McCamenband wunt (1965), containing 350uM acetyl $\left({ }^{14} \mathrm{C}\right)$ CoA. After incubation at $39 \mathrm{C}$ (Hebb et al, 1975) in the prescence of added choline and an aliquot of the subcelz 
Iular fraction being studied, $\left({ }^{14} \mathrm{C}\right)$ Ach is then separated from acetyl $\left({ }^{14} \mathrm{C}\right) \mathrm{COA}$ by liquid cation exchange with sodium tetraphenyl boron in a 3-heptanone $(5 \mathrm{mg} / \mathrm{ml})$ at an approximate 7 fold excess, according to the method pf Fonnum (1969). Aliquots of the 3-heptanone layer were counted in a toluene based scintillation fluid, and the amount of $\left({ }^{14} \mathrm{C}\right)$ Ach produced was calculated from the known specific activity of acetyl $\left({ }^{14} \mathrm{C}\right) \mathrm{CoA}$. Protein determinations were done according to the method of Lowry et al (1951). 
IITERATURE REVISW

Recently, the involvment of the central cholinergic system in mental disorders has been discussed (Davies et al, 1978). Cholinergic mechanisms may play a role in Huntington's disease and tardive dyskinesia, since the use of choline chloride may improve the involuntary movements involved in these diseases (Davies et al, 1976). Choline treatment can also be associated with an improvement in the symptoms of schizophrenics (see Davies et al, 1978), and anticholinergic drugs can aggravate schøzophrnia. Cholinergic underactivity may be involved in mania (Janowsky et al, 1972; Davies et al, 1975) an d euphoric manics less manic symptoms following cholinomimetic drugs, although irritable manics are not affected (Davies et al, 1978). The administration of acetylcholinesterasex(AchE) inhibitors has been reported to develop depression, and/or impaired memorye and concentrations (Rowntree et al, 1950; Gershon and Shaw, 1961; Bower et al, 1964; Medestein et al, 1973; Davies et al, 1977).

Choline-o-acetyltransferase (E.C.2.3.1.6.) (ChAT) catalyzes the synthesis of acetylcholine(Ach) in the following reversible reaction:

$$
\begin{aligned}
& \left(\mathrm{CH}_{3}\right)_{3} \stackrel{+}{\mathrm{NCH}} \mathrm{CH}_{2} \mathrm{OH}+\mathrm{COAS}-\underset{\mathrm{O}}{-}-\mathrm{CH}_{3}=\left(\mathrm{CH}_{3}\right)_{3} \stackrel{+}{\mathrm{NCH}_{2} \mathrm{CH}_{2} \mathrm{O}-\mathrm{CH}_{2}-\mathrm{CH}_{3}}+\mathrm{COA} \\
& \text { choline acetylCoA acetylcholine }
\end{aligned}
$$

ChAT was first discovered in tissue containing cholinergic nerve endings by Nachmansohn and Machado (1943), but it has been shown that the enzyme is poesent in nervous tissue rather than the tissue innervated (Bannister and Scrase, 1950; Collier and Katz, 1971; Hebb et al, 1964; Potter, 1970d.. 
ChAT is also found in the non-innervated placenta of higher primates (man and Rhesus monkey) although its functional role has not been determined (Hebb and Ratkovic, 1962; Morris 1966; Morris et al, 1971; Rama Sastry and Hendersen, 1972; White and Wu, 1973; Rama Sastry et al, 1976; Welch, 1976). ChAT is found in the bacterium, Lactobacillus Plantarum (Stevenson and Rowatt, 1947; White and Cavallito, 1970), and in the gill plates of pytilus edulis (Bulbring et al, 1953).

In nervous tissue, the distribution of the enzyme and ChAT activity is similar to the distribution of Ach and cholinergic nerves (Feldberg, 1945; Hebb and Morris, 1969; Kasa, 1971). The concentration and total amount of enzyme in human brain increases during fetal development (Bull et al, 1970); however, the level of ChAT activity in adult brain is less than the ChAT activity in nine year old human brain (Bull et al, 1970).

ChAT is synthesized within the cell bodies of cholinergic neurons and transported to the nerve terminal (Hebb et al, 1964 ) by fast or intermediate axpplasmic transport (Fonnum, 1973) and its half life has been reported in the range of 1221 days (Fonnum, 1973; Oesch, 1974). Neuronal activity may induce new Chat synthesis (Oech, 1974). Only 10\% of the total amount of ChAT present in ventral spinal neyrons is located in the cell body (Weil et al, 1977).

Under phsiological conditions, it is beleived that the majority of the enzyme is localized freely in the cytoplasm of the nerve ending (Fonnum, 1966; 1987; 1968; 1970; 1975) and not associated with synaptic vesicles or other membrane 
organelles in the presynaptic neuron (Whittaker et al, 1964). Vesicles containing Ach have been discovered in the nerve ending (De Robertis et al, 1963; Gray and Whittaker, 1962; Whittaker et al, 1964; Whittaker and Sheridan, 1965) and release of Ach from these vesicles has been postulated in accordance with the quantal hypothesis (Fatt and Katz, 1952). This hypothesis states that Ach, and other neurotransmitters within the nerve terminal, are released in discrete units, and elicit miniature endplate potentials (m.e.p.p.'s) of equal magnitude in the abscence of depolarization and a nerve impulse stimulates the nerve terminal to release quanta simultaneously, causing an increase in the frequency of m.e.p.p.'s, resulting in an end plate potential (e.p.p.).

The subcellular distribution of the enzyme is known to be be dependent and influenced by the conditions of synaptosomal hypo-osmotic shock (Fonnum, 1966; 1967; McCamen et al, 1965; Tucek, 1966). For all species, however, an increase in the ionic strength at physiological pH solubilizes ChAT from membranes, and a decrease in the lonic strength facilitates binding of the enzyme to membranes (Fonnum, 1966; 1967; 1968; Potter et al, 1968). The binding of ChAT to membranes is beleived to result from an ionic attraction between a positively charged enzyme and a negatively charged membrane (Fonnum, 1968). The isoelectric point and surface charge of ChAI differ in pigeon and guinea pig brain (Fonnum, 1968; Malthe-Sorensson and Fonnum, 1972), perhaps explaining the species variability observed in subcellular distribution studies. 
Two different forms of partially purified ChAT have been identified in human neostriatal tissue and can be distinguished by elution patterns from phosphocellulose columns, stability, and antibody producing capacity (Singh et al, 1975). ChATmmayy also exist in at least two forms in rat and cat brain (filtheSorensson, 1971; 1972) and in three forms in rat hippocampus, caudate nucleus, and sciatic nerve, indicating that in some species, closely related molecular forms of ChAT exist and these forms may differ in their membrane affinity.

The molecular weight of purified ChAT has been reported to be from 35,000 daltons (White and Cavallito, 1970) to 1,500,000 daltons (Chao and Wolfgram, 1974). The higher molecular weight forms of ChAT may have been produced by treatment of the initial extract with ammonium sulfate, since chao and Wolfgram (1974) have reported that this treatment may cause aggregation of ChAT. It has been shown that storage for 2 to 3 weeks at $-20 \mathrm{C}$ causes disappearance of the higher molecular weight forms (Banns, 1976). The apparent ammonium sulfate effect may be partially responsible for the multiple forms of ChAT found in rat and cat brains by isoelectric focusing techniques (Malthe-Sorensson and Fonnum, 1972) and the multiple forms found in human brain and sciatic nerve (White and Wu, 1973), since both groups of investgators used ammonium sulfate in their purification procedures. Evidence for isozymes of the 65,000 dalton form of ChAT may be limited to the asymmetrical peak of enzyme actirity obtained by Glover and Potter (1971). In contrast, the 65,000 dalton form of ChAT obtained by Chao and Wolfgram (1974) without the use of 
ammonium sulfate appeared to be of only one molecular species o f ChAT. In a later publication, Chao (1976) purified ChAT and found its molecular wieght to be 87,000 to 89,000 daltons and to have 6 identical subunits, although these are resistant to separation by a variety of techniques (Weber and Osborn, 1969; Swank and Munkres, 1971; Peterson, 1972; Moss and Rosenblum, 1972; Davies and Stark, 1970; Chao and Wolfgram, 1973). The amino acid sequence of the enzyme is known (Chao, 1976).

It should be noted that $15-30 \%$ of the total nerve ending ChAT remains attached to membranes (Hebb, 1972) and is beleived to be nonionically membrane bound (Kucenski et al, 1975). The cytochemical studies of Hattori et al (1976) and Feigenson and Barmett (1977) have suggested that at least some synaptosomal ChAT adheres to vesicles, and other investigations indicate that ChAT may be within vesicles (Hattori et al, 1978) and associated with the membrane of the presynaptic nerve ending (Barker and Mittag, 1975; Haubrich and Chippendale, 1977).

\section{THE MECHANISM OF SOLUBIIIZ ED ChAT}

The generally accepted mechanism for solubilized ChAT is the Theorell-Chance mechanism (Cleland, 1963) based on kinetic studies (White and Cavallito, 1970; Morris et al, 1971; Fendersen and Rama Sastry, 1972; White and wu, 1973; Emson et al, 1974), which predicts that the formation of an intermediate enzymeacetyl CoA-choline complex is immediately followed by product formation, thms permitting only a low concentration of intermediate to exist (Currier and Mautner, 1974; Malthe-Sorensson, 1976). Inhibition studies suggest the involvements of both a 
thiol group (Potter et al, 1968; Mannervik and Sorbo, 1970; Roskowski, 1973) and a histidine residue (White and Cavallito, 1970; Currier and Mautner, 1974; Roskowski, 1974). Thiol reagents such as p-chloromercuribenzoate, N-ethyl maleimide, iodoacetate, and 5,5'dithiobis-(2-nitrobenzoate (DNTB) appear to inhibit the enzyme, and acetyl CoA protects the enzyme from inhibition (Nalthe-Sorensson, 1976; Berman-Reisburg, 1957; Potter et al, 1968; Mannervik and Sorbo, 1970; Roskowski, 1974). However, the possibility exists that the action of the thiol reagents may be more peripheral in nature, causing conformational c anges and denaturation (White and Cavallito, 1970; Mannervik and Sorbo, 1970). Other complications include species differences in the sensitivity of ChAT to such reagents (Glazer, 1970; White and Cavallito, 1970).

The essential involvement of a histidine residue has been implicated by Malthe-Sorensson (1976) by incubation of the purified enzyme with diethylpyrocarbonate, and the formation of $\mathrm{N}$-cabithoxy histidine residues was measured. Imidazole residues have also been implied to be related to Ach synthesis by Hebb et al, (1975) and it can catalyze the formation of Ach nonenzymatically (Burt and Silver, 1973; Aquilonius, 1976). Imidazole has also been shown to activatew ChAT, sometimes by 80-100\% (White and Cavallito, 1970; Hebb et al, 1975).

Active ChAT has been immobilized on mercurisepharose gels (Malthe-Sorensson, 1976). The validity of this technique to study an enzymatic reaction may be questioned since it has beenshown that the immobiliza ion of enzymes to different types of supports changes their affinities for substrates, their pH optimum (Golstein et al, 1964; Homby et al, 1968) and their 
reaction kinetics (Kasche et al, 1971; Goldman et al, 1971). However, the number and type of different residues involved in the reaction meehanism are not beleived to change. The binding of ChAT to mercurisepharose gels is beleived to occurr at the thiol group in the active site, since preincubation of the enzyme in acetyl CoA inhibited binding to the gel. The bound emzyme is able to form Ach, indicating a nonessential thiol group (Malthe-Sorensson, 1976).

Further evidence implicating a functional histidine residue is provided by the fact that diethylcarbonate prevents the immobilized enzyme to form ACH (Malthe-Sorensson, 1976). In such a reaction meehanism, the rate limiting step would be the nucleophilic attack of histidine on acetylCoA with a fast reaction with choline (Bruice, 1959).

In a more recent study, it has been suggested that choline and acetyl COA bind in a random, not ordered, mechanism, since dead end complexes of enzyme-acetyl COA Ach and enzyme-cholineCoA were present, and the dossociation of COA appeared rate limiting in the forward reaction (Hersh and Peet,1978).

The effect of sodium chloride on the synthesis of ach in rat striated synaptosomes has been investigated (Guyenet et al, 1973), and decreased sodium concentrations are associated with decreased synthesis of Ach from glucose, but this inhibition can be reversed by the addition of choline, indicating that the reduction of Ach synthesis is not due to impaired metabolic activity (Guyenet et al, 1973).

Rossier et al (1977) have found that the chloride anion 
activates the $V_{\max }$ of unpurified solubilized ChAT from rat brain more effectively than several other anions, wheras the cation only affects the $\mathrm{V}_{\max }$ slightly. These investigators and others (Glover and Potter, 1971) have reported that purification procedures can affect the response of the enzyme to salts, and the enzyme's $\mathrm{K}_{\mathrm{m}}$ for choline and acetylCoA. Hersh et al, (1978) using a highly purified preparation of solubilized ChAT, has found that its activity is regulated by Ionic strength, and divalent cations such as $\mathrm{Mg}^{+2}$ and $\mathrm{Ca}^{+2}$ inhibit the enzyme already activated by $\mathrm{Na}^{+}$. In this study, the total anionic strength was able to influence ChAT's activity, and no selectivity for $\mathrm{Cl}=\mathrm{w}_{\mathrm{as}}$ found.

Therefore, it appears that solubilized Chat is able to catalyze the synthesis of Ach through an acetyl transfer by a histidine residue in the active site, and an apparently nonessential thiol is also in or near the active site (Currier and Mautner, 1974; Malthe-Sorensson, 1976). Furthermore, at physiological ionic strength, unpurified ChAT is activated by both sodium (Guyenet et al, 1973) and chloride inns fRossier et al, 1977), suggesting that elther or both may be necessary for the regulation and maintenance of ChAT activity(Hersh et al, 1978)

Kinetic studies, in addition to providing information about the mechanism of ChAT, also provide information concerming the concentrations of the substrates likely to be required for the synthesis of Ach in living tissue. Product inhibition studies can also reveal mechanisms by which ChAT may be regulated. $K_{m}$ values for choline and acetyl CoA are 
consistent across several species (see Table 1). It should be noted that Kucenski et al (1975) has described a membrane bound form of ChAT in rat brain, and found it to be kinetically similar to solubilized ChAm.

Although the mechanism of the reaction has not been elucidated with available kinetic evidence, it is generally agreed that a sequential mechanism exists and both substrates must interact with the enzyme before any products are released, (see review by Hebb, 1972). The products, Ach and CoA, have both been found to be inhibitory to Ach synthesis (FBtter et al, 1968; Kaita and Goldberg, 1969; Morris and Hebb, 1970; Morris et al, 1971; Glover and Potter, 1971; White and wu, 1973), and CoA has a $K_{i}$ similar to the $K_{m}$ of acetyl CoA. It should be noted that although high concentrations of Ach can be inhibitory to Ach production, the maximum ChAT inhibition attained by Ach is 50\% (Potter et al, 1968; Kaita and Goldberg, 1969; Glover and Potter, 1971).

\section{INEIBITORS OF ChAT}

To date, no inhibitor of ChAT has been found that produces effects on cholinergic transmission due to a direct inhibition of ChAT. In vitro inhibitors of ChAT include styrylpyridine analogues such as 4-(1-naphthylvinyl)pyridine (4-NVP), which are able to inhibit AchE to varying degrees (Smith et al, 1967; Cavallito et al, 1970; Goldberg et al, 1971; Krell and Goldberg, 1975), halogenated analogues of Ach (Chaseaand Tubbs, 1966; Morris and Grewaal, 1969; 1971), acroyloyl choline (Malthe-Sorensson, 1974), acetylsecohemicholinium-3 (Domino 
and 3-bromoacetonyl-trimethylammonium bromide., or bromoketone (Persson et al, 1967), although this last inhibitor has been shown to inhibit an enzyme capable of hydrolyzing acetylCoA in Purkinje cells of the cerebellum and sensory root ganglion cells (Kasa et al, 1970).

Of the styrylprridine analogues, Hebb (1972) has suggested that 4-NVP would inhibit ChAT specifically and not have significant action on cholinesterases. Goldberg et al (1971) has found that 4-NVP inhibits mouse brain ChAT in adose dependent manner in the range of 25 to $100 \mathrm{mg} / \mathrm{kg}$ in vivo, but maximum inhibition ( $* 43 \%$ ) occurred 4 hours after a $200 \mathrm{mg} / \mathrm{kg}$ i.p. injection. Signs of depression and ataxia were obstrved at this dose. 24 hours after a $200 \mathrm{mg} / \mathrm{kg}$ dose, no inhibition of ChAT was detectable. 4-NVF was able to inhibit the hexabarbitone-metabolizing enzyme system more effectively than ChAT in vitro, and the sleep time of mice was potentiated 3.5 fold by an i.p. dose of $25 \mathrm{mg} / \mathrm{kg}$ of $4-\mathrm{NVF}$ when given 30 minutes before barbituate treatment. The acute i.p. ID50 for 4-KVP at 24 hours was $337 \mathrm{mg} / \mathrm{kg}$. These investigations have also found that 4-NVP potentiated the behavoral effects of the ACh inhibitor physostigmine. Repeated attempt by several investigators to administer 4-NVD in vivo and reduce the levels of brain Ach levels have been unsuccessful (Carson, et al, 1972; Glick et al, 1973; Haubrich et al, 1974; Krell and Goldberg, 1975). One report indicates that i.p. administration of 200 or 400 $\mathrm{mg} / \mathrm{kg}$ of $4-\mathrm{NVP}$ to mice inhibits brain ChAT activity $65 \%$ without altering brain levels of Ach (Krell and Goldberg, 19750. 
Furthermore, Feigenson and Barrnett (1977) have reported in vitro with a partially purified mouse brain ChAT preparation 65. inhibition was attained with either a 5 or 10 up concentration of 4-NVP. Also, Aquilonius et al (1970) was unable to demonstrate any effect of 4-NVP on neuromuscular transmission in the cat that would be related to ChAT inhibition. These results were interpreted to indicate that brain ChAT activuty is not rate limiying in the formation of Ach by the nerve ending. An alternative possibility is that the majority of brain Ach may be synthrsized by ChAT which is in a subcellular location that is inaccessible to the inhibitor.

The in vivo administration of bromoacetylcholine, an effective in vitro unhibitor of ChAT (Morris and Grewaal, 1969; 1971), has been unsuccessful in reducing rat brain Ach levels, even after $93 \%$ of the Ach $\mathrm{E}$ had been inhibited, thus inhibiting the hydrolysis of the inhibitor, bromoacetylcholine (\$peth et al, 1976). No change in brain Ach levels were found, suggesting that either $7 \%$ of the normal AchE activity was sufficient to hydrolyze the inbibitor, or that spontaneous hydrolysis of the inhibitor occurred, since Hebb (1972) had found that at neutral $\mathrm{pH}$, these analogues are unstable.

\section{CHOLINE}

Free choline does not appear to be highly concentrated in cholinergic nerve endings (Mann and Hebb, 1977), its concentration in rat brain tissue being approximately 33uM (Stavinoha and Weintraub, 1974), about one tenth the $K_{m}$ for choline of 
solubilized ChAT. Therefore, changes in the intracellular choline concentration would be expected to affect Ach sththesis. The rate of release of Ach from the superior cervical ganglion of cat (Collier and Katz, 1974), rat (Sacchi et al, 1978), and mouse brain minces (Carroll and Goldberg, 1975) is enhanced when choline is present int perfusing or bathing medium. Choline induces an increase in the concentration of Ach in the hippocampus, a brain reqion rich in cholinergic nerve endings but not cell bodies, and denervation of rat adrenal gland abolishes this increase in Ach following choline administration (Faubrich and thippenadale, 1977).

Sources of free choline in the brain include dee novo synthesis, an extremely slow process if present at all(Freeman and Jenden, 1976), phospholipid degrafation, since choline phospholipids can be sydthesized in the brain or transported to the brain via the blood, suggesting that these compounds can be catabolized to form free choline (Ansee and Spanner, 1968; 1971; 1975; Illingworth and Portman, 1972; Hoelzl and Franck, 1973; Orlando et al, 1975), a base excange reaction in which choline may enter or be released from phosphatidyl choline directly (Abdel-Iatif and Smith, 1972; Brammer and Sheltawg, 1975; Dahlberg and Schuberth, 1977), and plasma choline which crosses the bl blood brain barrier, either by a saturatable uptake system (Sparf, 1973;Cornfed et al, 1977) or by diffusion (Freeman et al, 1975). Another source of choline in the brain is that choline produced by the hydrolysis of Ach b y AchE. 
The concentration of choline in the synaptic cleft produced in this way has been estimated to be in the millimolar range (Whittaker, 1963).

In light of the several sources of choline present in brain, it should be noted that the majority of releaseable Ach is derved frm extracellular choline (Gardiner, 1961; Browning and Schulman, 1968; Carroll and Goldberg, 1975), and that newly synthesized Ach is preferentialy released over preformed Ach (see review by Eebb, 1972). However, it has been shown that brain tissue can synthesize relatively large amounts of Ach when incubated in the abscence of choline (Browning and Schulman, 1968; Collier et al, 1972) indicating that both endogenous and exogenous stores of choline can be used for Ach synthesis.

Extracellular choline is transported into synaptosomes (Yamamura and Synder, 1972; 1973; Barker an d Mittag, 1975; Carroll and Buterbaugh, 1975) and minces (Carrolil and Goldberg, 1975) prepared from brain by two distinct uptake mechanisms, a high affinity system with $a \mathbb{k}_{t}$ of 0.5 to 5 uM and a low affinity system with a $K_{T}$ of 50-100uM. Most of the choline transported into synaptosomes by high affinity transport is beleived to be converted to Ach (Barker and Mittag, 1975).

The high affinity choline transport system is beleived to be localized specifically in cholinergic nerve terminals in brain (Kuhar et al, 1973; 1975) since denervation studies have shown that depletion of cholinergic nerve terminals is accompanied by a selective loss of high affinity choline transport

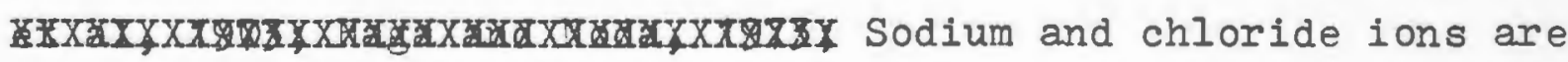
beleiveqg to be necessary for high affinity transport (Guyenet 
et al,1973; Haga and Noda, 1973; Simon and Kuhar, 1976; Kuhar 1978), as is a source of energy, since the metabolic inhibitor 2,4-dinitrophenol inhibits high affinity transport by $25 \%$ (Dowdall and Simon, 1973; vamamura and Synder, 1973; Simon and Kuhar, 1976), and a sodium-potassimum ATFase may be involved (chultz and.Curran, 1970).

Some attempts to couple high affinity choline transport and choline acetylation have suggested that choline must cross the high affinity transport system to be acetylated (Iefresne et al, 1975), while others (Barker and Mittag, 1975; Suszkiw and Pilar, 1976; Jope and Jenden, 1977) have fevored a kinetic coupling between transport and enzyme (controlled by the intracellular choline concentration available for Ach synthesis). Atterwill and Prince (1978) have suggested that one of the molecular forms of ChAT, which is present in adult rat brain but not in 7 day old brain, may be responsible for the couppling of high affinity choline uptake and choline acetylation. However, experiments with cat superior cervical ganglion suggest a lack of coupling (Collier and Ilson, 1977; Colli r et al, 1977) and in brain tissue (Barker, 1978).

In depolarized in vitro preparations, high afinity transpopt is reduced or lost, and choline taken up by the low affinity system is acetylated effeciently ( Carroll and Goldberg, 1975; Murrin and Kuhar, 1976; Vaca and Beach, 1977). However, direct elec trical stimulation of cholinergic tracts and administration of convulsant drugs in vivo have been shown to increase the $\mathrm{Vm}_{\mathrm{ax}}$ of high affinity choline transport (Atweh, et al, 1975; Simon and Kuhar, 1975; Jenden et al, 1976; Simon et al, 1976). 
In contrast to the high affinity choline transport system, low affinity transport is not beleived to be specific to cholinergic nerve endings (Diamond and Kennedy, 1969; Yamamura and Synder, 1973) and may supply choline for plospholipid synthesis.

Parental administration of choline may result in an increase in plasma and brain choline levels and barin Ach levels (Haubrich et al, 1974; 1975; Cohen and Wurtman, 1975). These results may suggest that the low affinity choline uptake is involved in Ach formation, and the elevation of plasma choline may promote Ach synthesis at sites remote from choli ergic terminals where only the low affinity transport system is operating. However, carnitine acetyltransferase, an enzyme present in brain tissue, may be able to acetylate chol ne (White and Wu, 1973; Schrier et al, 1974), although Bradshaw and Hemsworth (1976) have shown that carnitine is acewtylated 200 times as well as choline by carnitine acetyltransferase.

\section{CHOLINE ANALOGUES}

ChAT is not absolutely specific for its physiological substrate, choline (Hemsworth and Smith, 1970; Currier and Mautner, 1974; Barker and Mittag, 1975; Mann and Hebb, 1975; Collier et al, 1977; Ilson et al, 1977).

It has been assumed that the inhibition of Ach synthesis in synaptosomes by hemicholinium-3 (HC-3) is due to the inhibition of the choline uptake mechanism (Diamond and Kennedy, 1969; Fonnum, 1973). It has been argued, hoever, that the reversal of this inh bition by the addition of choline occurrs too slowly to be accounted for by a mechanism on the outside 
of the presynaptic membrane (such as a transport carrier), and that this reversal is more likely to occurr within the nerve ending (NacIntosh, 1963). In this regard several investigators have reported that $\mathrm{HC}-3$ can be acetylated by partially purified ChAT, although the identification of the acetylated product was incomplete (Arnaiz et al, 1970; Mann and Hebb, 1975; Barker and Mittag, 1975).

The choline analogue triethylcholine (TEC) is capable of prejunctional blocking action at neuromuscular junction (Bowman and Rand, 1961; Bowman and Hemsworth, 1965; Bowman et al, 1967), and Bull and Hemsworth (1955) and Potter (1968) have shown that TEC inhibits the transport of choline into nerve endings, suggesting that the pharmacological action of TEC is a reult of the depletion of available choline for Ach synthesis, leading to a decreased amount of releaseable Ach. In vitro, partially purified ChAT is capable if acetylating the mono-, di-, and triethyl analogues of choline, with monoehtylcholine (PIEC) acetylated almost as readily as choline, and the di- and triethyl choline analogues being less acceptable as substrates, respectively (Hemsworth and Smith, 1970). TEC was also found to be acetylated in vitro with a $\mathrm{K}_{\mathrm{m}}$ of 50mM (Mann and Hebb, 1975; Barker and Mittag, 1975). These studies were important since they suggest that TEC could be acetylated in vivo, and possibly form a false transmitter in cholinergic nerve endings. A false transmitter is a substance which is stored by a nerve terminal and released upon nerve stimulation under conditions which cause the release of the physiological transmitter. 
Ilson and Collier (1975) have demonstrated that the supcervical ganglion of the cat is capable of taking up TEC, acetylating TEC, and releasing acetyl-TEC in the prescence of $\mathrm{Ca}^{+2}$. Preganglionic nerve stimulation increases both the uptake and acetylation of TEC, al hough the large proportion of transported unacetylated TEC ( $76 \%$ of normal ) Suggests that the process if transport and acetylation are independent processes in ganglia (Ilson et al, 1977), at variance to the suggestion that choline uptake and acetylation are coupled (Barker and Mittag, 1975). In the rat cerebral cortex, 88\% of the total amount of TIC taken up remained unacetylated, and only $3 \%$ was acetylated after the tissue had been depolarized for 48 minutes prior to exposure to nondepolarizing medium with 10uM TEC (Ilson et al, 1977). The characteristics of the release of acetylTEC from brain tissue was similar to the characteristics of Ach release in brain tissue (Ilsonb et al, 1977); release was stimulated by high $\mathrm{K}^{+}$and atropine (Polak and Meuws, 1966; Bertel-Meuws and Folak, 1968) and was $\mathrm{Ca}^{+2}$ dependent (Molenaar and Polak, 1970; Molenaar et al, 1973; Carroll and Goldberg, 1975).

The choline analogue homocholine (3-trimethylamino-propan-1-ol) has been shown to block choline uptake in synaptosomes (Simon et al, 1975) and to be taken up by both a high $\left(K_{t}=3 u_{M}\right)$ and a low affinity $\left(K_{t}=14.5 u M\right)$ synaptosomal uptake system (Collier et al, 1977). Partially purified preparations of ChAT are unable to acetylate this analogue (Currier and Mautner, 1974; Collier et al, 1977), although synaptosomes are capable of forming acetyl-homocholine (Collier et al, 1977). 
A 3ur homocholine, the percent acetylation of the total amount of homocholine transported by synaptosomes is $32 \%$. The percent acetylation of total choline taken up by synaptosomes from a 3uri choline concentration $50.5 \%$, indicating that under these conditions, homocholine is almost as acceptable a substrate as choline (Collier et al, 1977). Synaotosomes incybated in higher concentrations of homocholine acetylated a much lower percentage of the total taken up than synaptosomes incubated in higher concentrations of choline (Collier et al, 1977).

Preganglionic berve stimulation of sympathetic ganglion accelerates the acrtylation of homocholine in the prescence of physostigmine, and the amount is $70 \%$ of the amount of choline acetylated under comparable conditions (Collier et al, 1976), although homocholine acetylation cannot be demonstrated with less than 60 minute stimulation (Collier et al, 1977). The amount of ho ocholine acetylated by stimulated ganglia is not enough to replace all the Ach released by nerve stimulation, and Collier e al (1977) has suggested that the rate of acetylation is limiting. Stimulated non-eserinized ganglia acetylated less than $10 \%$ of the accumulated homocholine, and release of acetyl-homocholine is $\mathrm{Ca}^{+2}$ dependent (Collier et al, 1977).

\section{ACETYI COA AND ANALOGUES}

The acetyl COA analogues, propionyl COA and butryl COA, can be uled for substrates for rat brain ChAT and have affinities equal to that of acetyl COA, although the $V_{\max }$ is decreased as the acyl chain lengthens (Rossier, 1977). Acetyl 
Acetyl COA for Ach synthesis can be produced inside the nerve ending from extracellular glucose, lactate, or pyruvate, but not exracellular succinate, citrate or acetate (Browning and Schulman, 1968; Jope et al, 1978). Acetyl CoA is formed from pyruvate, $\mathrm{NAD}^{+}$, and $\mathrm{COA}$ by prruvate dehydogenaase within the mitochondria (Sandi, 1963; Tucek, 1967). Transport of acetyl CoA directly out of the mitochondria is unlikely, since the mitochondrial membrane is poorly permeable to acetyl CoA (Tucek, 1967; Lowenstein, 1968). Tucek (1970) has suggested that mitochondrial contraction may promote lleakage of acetyl CoA out of mitochondria. Other transfer mechanisms of possible acetyl COA precursors out of mitochondria i clude transfer as citrate, acetate, and transfer as acetylcarnitine. However, the enzymes that catalyze the formation of acetyl CoA from acetate, acetyl CoA sunthetase (E.C.zZ6.2.1.1., acetate:CoA ligase), or from acetylcarnitine, carnitine acetyltransferase (E.C. 2.3.1.7. acetyl COA:carnitine-o-acetyltransferase) are found within the mitochondria (Barker et al, 1968; Neidle et al, 1969). Acetyl CoA synthetase is not foynd in sufficient quantities in the cytoplasm to maintain ach synthesis (Tucek, 1967).

Citrate is known to be transported into syaptws masx the cytoplasm of the cell from mitochondria for fatty acid synthesis (Barker et al, 1968). Citrate thus transported could then be converted to acetyl $\mathrm{COA}$ by the cytoplasmic emzyne cytrate ATP lyase (Tucek, 1967). It has been suggested that over $80 \%$ of the extramitomhondrial acetyl CoA produced from pyruvate in rat liver mitochondria is supplied via 
citrate ATP lyase (Daikuhara et al, 1968).-(-)Hydroxycitrate, an inhibitor of citrate ATP lyase, also inhibits incorporation of glucose into brain lipids, suggesting that citrate conversion to cytoplasmic acetyl $\mathrm{COA}$ is involved in brain lipid synthesis (Watson et al, 1969; Patel and Owen, 1976). Work wth mixed label glucose gas suggested that citrate is an intermediate in AcH synthesis (Sollenberg and Sorbo, 1970) and as the immediate precursor to the acetyl moiety of Ach (Sterling and O'Neill, 1978). The latter investigators have shown that the ${ }^{3} \mathrm{H} /{ }^{14} \mathrm{C}$ ratio of $\mathrm{Ach}$ produced is equivalent to the ${ }^{3} \mathrm{H} /{ }^{14} \mathrm{C}$ ratio of I acetyl COA produced by citrate ATP lyase, the citrate being produced intramitochondrially from $6\left({ }^{3} \mathrm{H},{ }^{14} \mathrm{C}\right)$ glucose. However, the ${ }^{3} \mathrm{H} /{ }^{14} \mathrm{C}$ ratio of $\mathrm{Ach}$ produced in the prescence of inhibitors of citrate cleavage, such as $-(-)$ hydroxycitrate, and n-butyl malonate, an inhibitor of citrate transport (Robinson and Chappell, 1967) is significantly higher that the ratio obtained in the abscence of inhibitors (Sterling and O'Neill, 1978), suggesting that alternative sources of acetyl CoA for Ach synthesis exist. It is important to note, however, that other investigations (Tucek and Cheng, 1974; Iefresne et al, 1977) have found that labelled citrate, which had entered the tissue, is not significantly incorpoated into Ach either

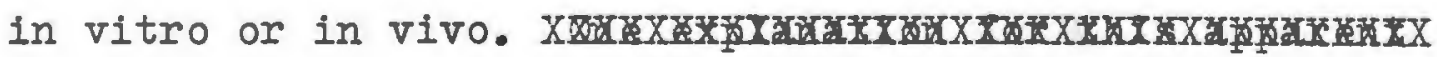

Feigenson and Barrnett (1977) have suggested that endogenous acetyl CoA stores are capable of producing a significant amount of Ach. It should be noted, however, that the source of endogenous acetyl COA is undetermined, and could be formed by alternate pathways to the citrate pathway. In brain tissue, 
acetate is not a precursor for Ach formation (Scuberth, 1965; Tucek, 1967; Neidle et al, 1969; Aas, 1971), as it is in neuromuscular junction (Dreyfus, 1975). Recently, diebler and Morot-Gaudry (1977) have found that, in the electric organ of Torpedo marmaruts, acetyl CoA synthetase is 30 times less efficient in producing acetyl COA than ChAD under optimum conditions, suggesting that this could be an alternative pathway of acetyl CoA production in brain tissue as well. Gibson and Blass (1976) have reported that Ach synthesis in mouse and rat brain is related to the NADFNADI ratio in both the cytoplasm and across mitochondrial membranes, but may not be related to a decrease in ATP or adenylate energy charge. These results imply that several sources of acetyl CoA fo $r$ Ach synthesis may exist.

\section{REGULATION OF ChAT}

Regulation of ChAT activity is beleived to exist peripherally, since Ach release promotes increased synthesis so that tissue levels are maintained at normal levels (Birks and MacIntosh, 1961; Br wring ang Schulman, 1968; Carroll and Goldberg, 1975; Sacchi et al, 1978). This regulation may occurr by product inhibition, but Ach has been found to be a weak inhibitor and is only capable of a 50\% inhibition of enzyme activity at Ach concentrations of $100 \mathrm{mM}$ or more (Potter et al,1968; Kaita and Goldberg, 1969; Glover and Potter, 1971). Heterogeneity may exisrt, since Singh et al (1975) have reported that one molecular form of ChAT, a low activity form, is less resistant to Ach inhibition than a higher activity form. CoA is a much more effective inhibitor of Ach synthesis, but the accumulation 
of CoA under physiological conditions is thought to be unlikely, since the ratio of CoA to acetyl CoA would be expected to change during Ach release, an these changes would affect the synthesis of other acetyl CoA requiring materials such as fatty acids (Hebb, 1972).

Another possible watk ChAT may be regulated is by substrate arailability. For acetyl COA to limit the activity of ChAT, its avallability would have to increase during Ach release. While no direct evidence exists that supports this possibility, it is beleived that $\mathrm{Na}^{+}$, whose intracellular levels increase as a result of depolarization, increase the oxidation of glucose to $\mathrm{CO}_{2}$ ((Diamond, 1971), suggesting that the amount of Krebs cycle intermediates produced may be enhanced. It should be noted that Ach synthesis is beleived to be somewhat $\mathrm{Na}^{+}$ dependent (Mann and Hebb, 1975; Hersh et al, 1978; Jope and Jenden, 1978), as is high affinity choline uptake (see Kuhar and liurrin, 1978). Conditions of hypoxia or hypogylcemia inhibit the production of Ach (Gibson and Blass, 1977).

The rate of Ach synthesis in nerve terminals may be related to high affinity choline yptake (Barker and rittag, 1975; Guyenet et al, 1973), and this uptake mechanism may be stimulated by in vivo treatment with drugs that lower levels of brain Ach (Jenden et al, 1976) or direct electrical stimulation that stimulates nervous activity (Simon and Kuhar, 1975; Atweh et al, 1975; Simon et al, 1976). High affinity choline transport is reduced or lost in depolarized in vitro preparations (Carroll and Goldberg, 1975; Murrin and Kuhar, 1976; Vaca and Beach, 1977), and choline uptake is accelerated (Roskowski, 1978), 
probably mediated by the low affinity transport system, and acetylated efficiently, Experiments with sympathetic ganglia suggest that preganglionic nerve stimulation increases the total uptake of choline (Collier and MacIntosh, 1 969; Collier and Katz, 1976), and de-emphasizes the importance of high affinity choline uptake for Ach synthesis in ganglia. Furthermore, lesioning of the preganglionic nerve terminal has no influence on choline transport supplying the substrate for acetylation (Katz and Collier, 1974).

It has been suggested that neuronal activity may increase the production of ChAT in the cell body (Oech, 1974), but it is beleived that enzyme activity is not rate limiting for Ach synthesis, since Ach synthesis by brain in vivo is approximately 30 fold less than that found in vitro (Schuberth et al, 1970; Hebb, 1972; Saelens et al, 1973; Jenden et al, 1974) and inhibitors of ChAT do not appear to lower Ach levels (Glick et al, 1973; Krell and Goldberg, 1975). If neuronal activity enhances ChAT production and ChAT were rate limiting, the amount pf Ach synthesized in the tissue during depolarization would be expected to increase. This is not beleived to occurr peripherally. It may be possible that the enzyme may be released during depolarization, since dopamine beta hydroxylase has been shown to be released (DePotter and Chubb, 1971).

\section{TIEE QUANTAI THEORY AVD VESICLE HYPOTHESIS}

The existence of minute transient fluctuations in voltage (m.e.p.p.'s) at neuromuscular junctions (Fatt and Katz, 1950; 1953) and at central synapses in spinal motoneurons (Katz and 
Miledi, 1963) are beleiv d to represent the release of quantal units of transmitter, such as Ach, into the synaptic cleft. Furthermore, m.e.p.p.'s exhobit a regular size and time course, indicating that these changes in the end plate potential are not due to leakage of Ach, but from the simultaneous release of thousands of Ach molecules which are highly concentrated (Katz, 1966). The realease of these multimolecular packets of Ach in an all or none fashion from discrete points of the terminal axon menbrane is the basis of quantal spontaneous release (Katz, 1966). Eachquantum of Ach is thought to contain 5,000 to 10,000 molecules, and the release of large numbers of quanta is thought to cause the generation of an end plate potential or a postsynaptic potential (Katz and Miledi, 1963; Katz, 1966; 1969).

The significance of the quantal theory was enhanced by the electron-microscopic observation that synaptic vesicles (40-50 nm in diameter) were concentrated at both neuromuscular junctions (Robertson, 1956) and central synapses (DeRobertis and Bennet, 1954; 1955; Fermandez-Moran, 1957). Subcellular fractionation studies found that pinched off nerve endings, or synaptosomes, contained Ach, ChAT, and AchE, and vesicles contain the highest concentration of Ach (Whittaker , 1959; Gray and Whittaker, 1962; DeRobertis et al, 1963; Whittaker et al, 1964; Whittaker and Sheridan, 1965). The relationship between the sy apyic vesicles and Ach led to the development of the vesicle hypothesis, which states that the transmitter substances are stored within synaptic vesicles which are then conveyed to the presynaptic membrane by some unkown process, and the 
release of onexs vesicle's content corresponds to the release of one quantum (Jones, 1975), although most estimates of vesicle content indicate that a one-to-one relationship between quantum and vesicle is unlikely (Whittaker, 1970; Whittaker and Sheridan, 1965). It should be noted, however, that the quantal nature of Ach release in cerebral cortex has not been demonstrated. The response to Ach by cholinoceptive cells is slow and prolonged in cerebral cortex (Krnjevic et al, 1971d), while a rapid and brief response to Ach is seen at the endplate region of skeletal muscle (Krmjevic and Miledi, 1958).

DOOLSOF Ach

IREE Ach

20-30\% of the total brain Ach content is released upon homogenization, is susceptible to AchE hydrolysis (Crossland and Slater, 1968; Tobias et al, 1946), and is thought to be outside of the nerve ending, probably that present in cholinergic axons, which are known to contain Ach along their whole length (MacIntosk, 1941). The source of the Ach in the axon maybe due to the fast axoplasmic transport of Ach storage particles or Ach bound to particles (Evans and Saunders, 1967; Schafer, 1973), or the simultaneous transport of ChAT, choline, and acetyl CoA (Fonnum et al, 1973; Hodgkin and Martin, 1965). The functional significance of this pool of Ach is unknown.

\section{BOUND ACh: CYMOFIASMIC AND VESICULAR}

- The remaining Ach is bound within synaptosomes, and these particles can be disrupted by hypo-osmotic treatment (DeRobertis 
et al, 1963; Whittaker, et al,1964) or pressure under isoosmotic conditions (Takeno et al, 1969). After synaptosomal rupture, about half of the total bound Ach is released and is susceptible to AchE hydroylsis (cytoplasmic Ach); the remaining Ach (vesicular Ach) is protected from Ach $\mathrm{E}$ and is found in the pellet of high speed centrifugation of lysed synaptosomes (DeRobertis et al, 1963; Whittaker and Sheridan, 1965). Exposing intact cerebral cortex to radioactive choline has been shown to labell these two nerve ending stores with specific activities (Aquilonius et al, 1973; Molenaar and Polak, 1973; Molenaar et al, 1973; Richter and Marchbanks, 1971), and the amounts of choline present in these stores can change independently (Collier et al, 1972), suggesting that cytoplasmic Ach is at least not entirely due to leakage from vesicular Ach.

IOCALIZATION OF ChAT

Fonnum (1975) has estimated that in the CNS, 5\% of the total ChAT activity present is localized in the cell body, 15-25\% in the axons and dendrites, and 70-80\% in the nerve terminal. It was found that the location of ChAT within the nerveterminal, between the cytoplasm and membrane particles, including vesicles, was affected by the severity of the treatment used to hypo-osmotically shock synaptosomes, since DeRobertis et al (1963), who resuspended stynaptosomes in 9$10 \mathrm{mls}$ of water per gram of tissue, found that ChAT was localized with heavy membrane particles, including vesicles, and Wh ttaker et al, (1964), who resuspended synaptosomes in $2 \mathrm{ml}$ of water per gram of tissue, found that most of the ChAT was 
activity appearred in the high speed supernate, suggesting cytoplasmic location. An explanation for these apparently divergent results was found by Fonnum (1967; 1968) who found that the proportion of solubilized to membranee bound ChAT in synaptosomes was largely a function of the ionic strength and $\mathrm{pH}$ of the suspending medium, maximum release of membrane bound enzyme occurring at an ionic strength of $150 \mathrm{mM}$ and a $\mathrm{pH}$ of 7.4 . Furthermore, these studies suggested that species specificity is a factor, since rabbit and rat brain ChAT is more resistant to solubilization than ChAT from guinea pig and pigeon enzymes.

\section{CIASSICAL HYPOTHESIS}

Based on these findings, the classical hypothesis of Ach synthesis, storage and release was formulated by Fonnum (1975). According to this hypothesis, all Ach synthesis occurrs in the nerve ending cytoplasm, where the majority of ChAT is localized (Fonnum,1967; 1968). During nerve depolarization, Ach is released from the vesicular stores of the nerve terminal, and the Ach synthesized in the cytoplasm is then beleived to be transported by some mechanism into vesicles, and then released. A possible mechanism for the release of Ach from vesicles has been envisioned by Katz (1969), in which vesicles release their contents upon collision with reactive sites at the synaptosomal membrane. The choline uptake system, most probavly the high affinity system, is beleived to supply the cytoplasm with the choline necessary to maintain intracellular Ach levels (Fonnum, 1975).

The major weakness of this hypothesis is that two pools 
of Ach are found in synaptosomes, thecytoplasmic and vesicular pools, and only one site of synthesis, the cytoplasm (see Hebb, 1972; see Fonnum, 1975). The transport of cytoplasmic Ach into vesicles above diffusion levels has not yet been shown (Marchbanks, 1968; Katz et al, 1973; Suszkiw and Pilar. 1976; Carroll and Nelson, 1978), although binding of Ach to vesicles has been demonstrated (O'Brian 1976). The inability of vesicles to concentrate Ach supplied extravesicularly questions the supposed transfer of Ach from the Cytoplasm to the vesicles, since the vesicular concentration of Ach is estimated to be considerably higher than cytoplasmic Ach. Furthermore, it has been reported that the vesicular pool of Ach can empty and be refilled independently of the cytoplasmic pool (Carroll and Nelson, 1978), and that all of the vesicular Ach is replaced with newly synthesized Ach formed from extracellular choline rather than extracellular Ach.

These investigations also suggest that synthesis of Ach destined to be incorporated in the vesicles occurrs at aome other site than the cytoplasm. It should be noted that Kucenski et al (1975) described a membrane bound form of ChAT from rat brain, and two components of Ach synthesis have been observed in brain cells in culture ( ). Recent cytochemical studies have suggested that at least some ChAT is associated with vesicular membranes (Feigenson and Barrnett, 1977) and the number of vesicles present in the nerve ending may be related to the amount of active ChAT which can be found on vesicular membranes (Barrnett et al, 1978). Hattori et al (1976) has also reported that ChAT may be associated with both the outside of vesicular membranes and possibly intra- 
vesicularly. The mean half life of vesicles, 21 days, (Amaiz et al, 1970), agrees well with the estimated half life of ChAT, 12-20 days (Fonnum et al, 1973).

Arguments against the intravesicular location of GhAT state that acetyl CoA generating enzymes, which have not been found in vesicular fractions of brain (Tucek, 1967), must be present, along with substrate and ATP. However, Feigenson and Barrnett (1977) found that an endogenous pool of acetyl CoA in rat brain synaptosomes which is able to support Ach synthesis at $20 \%$ of normal amounts. The work of Lai et al (1977) may provide evidence that the vesicular fraction of acetyl COA may be related to the apparent heterogeneous nature of brain mitochondria ( $\operatorname{Van}$ der Serg, 1973). Two mitochondrial populations were found in rat brain, and both fractions were contaminated with membranes and Vesicles.

Another argument against the intravesicular production of Ach involves the generation of intravesicular CoA, a stong inhibitor of ChAT (Fotter et al, 1968; Glover and Botter, 1971; Hebb, 1972), and would not allow the intravesicular Ach concentration to reach more than micromolar levels, assuming that CoA cannot be transported out of the vesicle.

\section{FINE STRUCTURE OF THE PRESYNAFTIC NERVE TERMINAL}

Several structures have been identified in the presynaptic nerve terminal (see Jones, 1975; 1978). These structurs mat indicate that the activities of the cytoplasm do not occurr in a random fashion. 
The ording of the area at the presynaptic terminal is emphasized by the prescence of a presynaptic vesicular grid, which appears to define the sites at which the vesicles can make contact with the presynaptic membrane (Jones, 1972). The observation that dense projections, exist as regularly arranged profiles projecting from the presynaptic membrane into the cytoplasm (Gray, 1963; 1966) may suggest that these projections are involved in drawing synaptic vesicles towards the presynaptic membrane prior to neurotransmitter release (Gray, 1966). Seversl investigations have suggested that dense projections are essential to presynaptic organization (Akert et al, 1969; Pfenninger et al, 1969; Akert, 1973), since they may be the nodal points of hexagonally arranged vesicles (Akert et al, 1969;1975; Akert and Pepu, 1975) and interconnected by filamentous strands.

Protuberances along the presynaptic neuronal membrane may represent temporary attachment sites for vesicles and constitute channels for the release of neurotransmitters from the vesicles trhough the presynaptic membrane (Del Castillo and Katz, 1957), or the protuberances may be the result of the release of neurotransmitter by an exocytotic mechanism (Streit et al, 1972; Jones, 1975).

Although vesicle loss upon stimulation has been observed by Barmett et al (1978), the phenomenon is not well established (see Boyne, 1978). The long half life of vesicular membranes (Arnaiz et al, 1970) may be interpreted as evidence against exocytosis as a mechanism for transmitter release, since exocytosis implies single usage of the vesicle, and therefore a 
high turnover rate (Cooper et al, 1977). Furthemore, Barker et al (1970) has suggested that the protein and lipid profiles of the vesicular and nerve terminal membrane are different, implying that fusion of vesicles with the nerve terminal membrane is unlikely. Another exptanation for vesicle loss may be an alteration in vesicular shape and configuration. After stimulation, vesicles appear to become elliptical in frog neurmuscular junction (Feuser and Reese, 1973). In apparent support of exocytosis, vesicles appear to be released from electric organ of the electric ray (Boyne et al, 19750 and from cat superior cervical ganglion (Eysh and Wiley, 1974). Coated vesicles, which have been assigned roles in the unfolding and fissioning of cell membranes (Roth and Porter, 1974), the cellular uptake and transport of proteins (Roth and Porter, 1974; Friend and Farquhar, 1967; Bowers, 1964) and enzymes (Broni et al, 1965; Holtzman et al, 1967), consist of a central vesicle surruonded by hexagonal and pentagonl shapes (Kanaski and Kadota, 1969; Kadota et al, 1976) composed of one protein, clathrin (Pearse, 1975). Coated vesicles have higher activities of certain enzymes than plain syna.ptic vesicles (Kadota and Kadota, 1973) and vesicular choline is preferntially associated with coated vesicls, while vesicular Ach is predominant in plain synaptic vesicles (Kamiya et al, 1974). Coated vesicles also appear to be preferntially located in the Eytoplasm of the nerve ending (Gray, 1972; Jones and Bradford, 1971), and have been implicated in the transfer of membrane between the presynaptic and vesicular membranes (Marchbanks, 1976). The presynaptic network is beleived to be 
of a microfilamentous nature of unknown components, extending throughout the presynaptic terminal and attaching at various points along the inner membrane of the presynaptic terminal, and may condense during fixation procedores to artifactually create coated vesicles (Gray, 1972; 1973; 1975).

It has been found bt Grat (1975) that microtubules can be found in presynaptic nerve terminals, and other investigat파요 have implied a close association of vesicles and microtubules in axons of larval lamprey spinal cord (Smith et al, 1970; 1971). Complexes of microtubules and smooth endoplasmic reticulum have been found in CNS tissue, but rarely at presynaptic nerve terminals (Grahinger and James, 1969; Iieberman, 1971). Microtubules are beleived to be involved in rapid directional translocation of intracellular particles (Smith et al, 1975). In nerve cells, they may be involved in axoplasmic transport (Paulsen and McClure, 1975). The mitotic inhibitios viblastine and colchicine disrupt tubulin polymers and xaxidx block rapid transport of protein (Karlsson and Sjostrand, 1969; 1971) and noradrenergic vesicles (Banks et al, 1971; 1972). The rate of tubulin production may be associated with functional stimulation, since eye opening causes a rise in tubulin synthesis in visual cortex (Roset et al, 1976; CronlyDillon and Perry, 1976).

Actomyosin proteins have also been found in presynaptic terminals (Fine and Brag, 1971; Fushkin and Berl, 1972; Bunge, 1973). It has been postulated that an interaction between membrane associated actin and cytoplasmic myosin may draw the synaptic vesicles towards the terminal membrane ( Le Beux and 
Willemot, 1975).

Synaptosomes have been shown to contain some of these structures (Jones etaal, 1975). Synaptic vesicles, coated vesicles, and dense core vesicles have been found using combined aldehyde-O $\mathrm{SO}_{4}$ fixation and staining with uranyl and lead salts (Kuriyama et al, 1958; Ross et al, 1971; Dowdall and Whittaker, 1973), and dense projections and the presynaptic network have been revealed have been visualized using a non-osmicated fication technique (Bloom and Aghajanien, 1966; Jones, 1969; 1970). 
HATERIAIS AND METIOODS

EREIARATION OF MOUSE ERATN CEOLINE-O-ACETYLTRAISPERASE

Male (CD-1) albino mice were killed by cervical dislocation in a cold room ( $4 \mathrm{C}$ ), the brains quickly removed, and placed in several hundred millimeters of ice-cold $0.32 \mathrm{M}$ sucrose (isotonic sucrose). The brains were then blotted dry, the cerebellum, pons, medulla, and optic buttons excised, and sectioned through the medial saggital fissure. The brain halves were weighed, minced, and stored on a petri dish on ice until the onset of incubation.

To reduce the tissue levels of Ach which may be inhibitory to the enzyme (Potter et al, 1968; Kaita and Goldberg, 1969; Glover and Potter, 1971), the brain minces, wieghing approximatelt 150-200mgs, were incubated in $8 \mathrm{mls}$ of $35 \mathrm{mMr}^{+} \mathrm{Krebs}$ bicarbonate buffer medium(1012 $\mathrm{mM} \mathrm{NaCl} ; 3.5 \mathrm{mMKCl} ; 2.5 \mathrm{mM} \mathrm{CaCl}$; $1.2 \mathrm{KH}_{2} \mathrm{PO}_{4} ; 1.2 \mathrm{mM} \mathrm{MgSO} 4 / 7 \mathrm{H}_{2} \mathrm{O} ; 28.0 \mathrm{mM} \mathrm{FCO}_{3} ; 11.11 \mathrm{mM}$ glucose) at $37 \mathrm{C}$ for 4 minutes under $95 \% \mathrm{O}_{2}-5 \% \mathrm{CO}_{2}$ in a Dubnoff metabolic shaker, set a 90 cycles/minute (Salemoghaddam and Collier, 1976; Carroll and Goldberg, 1976). The incubated minces were then washed twice with ice-cold isotonic sucrose, and subaellular fractions prepared according to the method of Gray and Whittaker (1962) as modified by Collier et al (1972) and Salemoghaddam and Collier (1976) (see Fig. 1). The washed minces were homogenized in $5 \mathrm{ml}$ of isotonic sucrose at 840 RPM using 8 up and down strokes in a Teflon to glass homogenizer, with a clearance of $0.025 \mathrm{~cm}$. This initial homogenate was centrifuged at $4 \mathrm{C}$ at $1000 \mathrm{~g}$ for 10 minutes and the pellet, $\mathrm{P}_{1}$, which is composed primarily of nuclear debris and myelin, was discarded. The 
supernate, $S_{1}$, which inclides nerve ending synaptosomes, was centrifuged at $17,000 \mathrm{~g}$ for 15 minutes. Following this centrifugation, the supernate $\left(S_{2}\right)$, which contains microsmes, was discarded. The synaptosomal fraction $\left(P_{2}\right)$, which Exyms is rich in synaptosomes (De Robertis et al, 1963; Gray and Whittaker, 1962; Whittaker et al, 1964), was the hypo-osmotically shocked in $2 \mathrm{mls}$ of ice cold glass distilled water, pF 4.0 , and homogenized at 400 RPM with a Teflon to glass homogenizer using 8 up and down strokes, in a effort to maximize synaptosomal rupture. This homogenate was then centrifuged at $100,000 \mathrm{~g}$ for 60minutes to yield a pellet $\left(F_{3}\right)$ and a supernate $\left(S_{3}\right)$. The $\mathrm{P}_{3}$ fraction, or the crude vesicular fraction, consists of synaptic vesicles, ruptured synaptosomal menbranes, mitochondria, and most of the synaptosomal ChAT activity, since ChAT has been shown to bind to membranes under conditions of low ionic strength (Fonnum, 1967; 1968). The $\mathrm{S}_{3}$ fraction contains cytoplasmic Ach and other cytoplasmic constituents. The $\mathrm{P}_{3}$ fraction was then suspended twice in one $\mathrm{ml}$ of $100 \mathrm{mll}$ sodium phosphate buffer, $\mathrm{pH} 7.4$, ionic strength $160 \mathrm{mM}$, and centrifuged for 60 rinutes at $100,000 \mathrm{~g}$. The supernates from these two centrifugations were then combined, and contain that fraction of synaptosomal ChAT which is ionically bound to membranes after hypo-osmotic synaptosomal rupture, and beleived to exist freely in the cytoplasm of the cholinergic nerve ending in vivo (Fonnum, 1967; 1968; 1975). The washed $P_{3}$ fraction was then surface washed twice with 10mls of glass distilled water, $\mathrm{pH} 4.0$, in an effort to reduce endogenous choline. The enzyme activity in the washed crude vesicular fraction is beleived to be due to a form of ChAT which is non-ionically bound to membranes or 
membrane organelles.

The recivery of ChAT and protein of the synaptosomal fraction $\left(P_{2}\right)$ is shown in Fig. 1 .

\section{ASSAY FOR ChAT ACTIVITY}

ChAT activity in the mouse brain sucellular fractions was determined by the procedure of liccamen and Hunt (1965) as modifoed by Spyker et al (1972). In this procedure, a saturating acetyl $\left({ }^{14} \mathrm{C}\right) \mathrm{CoA}$ concentration and various concentrations of unlabelled choline are incubated in a $200 \mathrm{mM}$ sodium phosphate buffer, pH 7.4, in the prescence of an aliquot of the subceilular fraction in question. Aliquot volume was $2 u l$, and the buffer substrate mixture, containing acety $\left({ }^{14} \mathrm{C}\right) \mathrm{CoA}$, choline, sdium phosphate buffer, $\mathrm{NaCl}, \mathrm{MgCl}_{2}$, and $70 \mathrm{mg} / \mathrm{ml}$ protien, had an aliquot volume of $20 \mathrm{ul}$. The acetylated product was extracted from the inषubation mixture with $5 \mathrm{mg} / \mathrm{ml}$ sodium tetraphenyl boron in 3-heptanone via cation exchange (Hebb et al, 1975). Tissue-free samples were run as blanks.

X7x.r. Imidazole groups have been implicated as activators of the non-enzymatic production of Ach from choline and acetylCoA (B Eebb et al, 1975; Aquilonius, 1976). Therefore, control (tissue-free) and enzyme containing incubation mixtures were boiled for 5 minutes, an found to be not to be significantly different from values obtained for the nonboyise ${ }^{c}$ control control (tissue-free) incubabation mixture.i

Protein was determined by the method of Iowry et al, 1951. DECSENDING FADER CHROMATOGRAPHY 
Ach (and other acetylated products) extracted into sodium tetraphenyl boron in 3-heptanone was extracted into $0.4 \mathrm{~N} \mathrm{HCl}$ 鲭坛 recovery of $85 \%$ (Nelson, personal communication), and lyophilized and concentrated several fold. The concentrated samples were straked on Whatman No. 5 chromatogrm paper and developed, in a descinding fashion, in a solvent system of n-butanol-ang $(8: 2: 1: 3, v / v)$ at room temperature for 8 hours. An Ach standard (unlabelled) was co-chromatographed and ita position detected by iodine vapor (Brante, 1949). The developed chromatograms were cut into $1 \mathrm{~cm}$ strips, eluted with $1 \mathrm{ml}$ of hyamine-methanol $(1: 2) \mathrm{v} / \mathrm{v})$, and counted by liquid scintillation spectrometry, using a tolune based fluor.

In some experiments, the incubation mixture contained no mradded choline, and endogenous stores of substrates for mouse brain ChAT, including choline, were acetylated with acetyl $\left({ }^{14} \mathrm{C}\right) \mathrm{CoA}$. The prescence of $\mathrm{Ach}$ and at one other acetylated compound with a quaternary ammonium group has been determined under these conditions.

In other experiments, a vast excess of AchE was present in the incubation mixture, based on the amount of Ach formed by the fraction under study, and the prescence of non-hydrolyzed Ach was confirmed by descending paper chromatography.

\section{INEIBITION STUDIES}

Solutions of 4-(1-naphthylvinyl)pyridine (4-NVF) were prepared in amber bottles, since 4-NVP is light-sensitive 
(White and Cavallito, 1970). The increase in volmme of the incubation mixture was $1 \mathrm{ul}$, and the increase in total volume did not effectively dilute tha Ach produced.

When the effect of 4-IVP was measured in vivo, mice were pretreated with either an i.p. injection of 4-NVP in saline or an equal volume of saline, and were killed by cervical dislocation 30 minutes later. Subcellular fractions were prepared as descibed as above, and ChAT activity was determined.

Inhibition of mouse brain ChAT in vitro by Ach was investigated by adding 1 ul of a highly concentrated Ach solution to the incubation mixture immediately before the incubation if the sample, in an attempt to decrease the amount of choline produced by the reverse reaction of ChAT from the added Ach. The forward reaction is hoghly favored and has an equilibrium constant of approxinatel 500 (Potter and Glover, 1971).

\section{IOCOIOTOR ACTIVITY MEASUREMISHTS}

In these experiments, 4 mice were injected i.p. with $200 \mathrm{mg} / \mathrm{kg} 4-\mathrm{NVP}$, an equal volume of saline, or not injected, the latter acting as a control for injection. Locomotor activities were determined for gruop of adult mice in activity chambers equipped with a Selective Activity Meter - Model S and activity measurements were recorded at 15 minute intervals. Two different chambers were used, and the activity obtained at the initial 15 minutes for the non-injected control group for each activity chamber was arbitrarily set at 100\%. 
Choline Analogue Synthesis

Homochaline and triethylcholine iodide salts were prevpared by reacting the corresponding tertiary amino alchols, 3-di-methy amino-1-proparal an 2-diethyl amino ethanol, with methyl a ethyl iodides, respectively. The reactions wee spontaneous at room temperature or upon gentle warming, respectively. Homogeneity of both of these analogues was ascertained by descending paper chromatography and found to agree with other investigators (Barker and Muttag, 1275; Collier ital, 1977; Olson et al, 1977). 
AIATYSIS OF ENTYIE KINETICS

The steady state kinetics of the great majority of enzymecatalyzed reactions can be described in terms of a hyperbolic relationship between the velocity of the reaction, defined in this study as the activity of ChAT at a known choline concentration, and the concentration of choline involved (Roberts, 1971). The doble reciprocal plot, in which $1 / v$ is plotted against $1 / \mathrm{s}$, is by far the most widely used transformation to study enzyme kinetics (Iineweaver and Zurke, 19 ). This transformation was used in this study.

\section{SMATISTICS}

The statistics used in this investigation include the paired and independent t-tests, as described by Lentner (1975).

\section{LII:ITATIONS OF THIS STUDY}

The major assumptions of this approach include the use of high potassium concentrations to induce vesicular Ach release as a valid technique (Liley, 1956; Katz, 1962; Gaye, 1967), and that ChAT is specific for cholinergic neurons (Fonnum, 1979). The major weakness of this approach is that central Ach metabolism is studied in an in vitro preparation which has been estimated to beonly $15 \%$ cholinergic (MacIntosh, ), and the degree of interaction with noncholinergic neurons has not been determined. 


\section{INATERIALS}

Acetylcholinesterase(Ach $\mathrm{S}$ ) and 4-NVP were purchased from Sigma and Calbiochem, repectively. 2-Diethylaminoethanol and ethyl lodide, the corresponding amino alcolhols and alkyl iodide for the synthesis of triethylcholine (TEC), were supplied by Eastman and Fischer Scientific, respectively. 3-Dimethyl amino-1-propanol and methyl lodide, the corresponding amino alcohol and alkyl iodide for the synthesis of homocholine, were supplied by Aldrich Chemical. Acetyl $\left({ }^{14} \mathrm{C}\right)$ CoA was purchased from New England Nuclear, with a specific activity of 10.1 n Ci/mble. Toluene and Iiquifuor were purchased from Fischer Scientific and New Eugland Nuclear, respectively. 
is desci

The subcellular fractionation procedure used in this study is described in Fig. 1. The recovery of synaptosomal ChAT and and protien is shown in Table 1, and these results are similar to those obtained by Fonnum (1968).

The results shown in Fig. 2. Indicate that both the solubilized and membrane bound forms of mouse brain nerve ending ChAT can linbarly acetylate choline for 30 minutes, when saturated with both choline and acetyl COA at $39 \mathrm{C}$. The membrane bound form of the enzyme appears to acetylate choline linearly for almost an hour under these conditions. The nonenzymatic conversion of choline and actyl CoA to Ach has been shown to exist and be enhanced by imidazole groups in extracts of rat brain (Hebb et al, 1975) and human cerebrospinal fluid (Aquilonius and Eckernas, 1976). To test the possibility that nonenzymatic production of Ach was occurring, both the solubilized enzyme form,present in the combined sodium phosphate wash fraction, and the membrane bound form of ChAT, present in the washed crude vesicular pellet, was boiled for 5 minutes and their respective abilities to form Ach from saturaring levels of choline and acetyl COA determined. Boiling reduced the activity of both enzyme forms to the level of tissue free blanks, suggesting the abscence of nonenzymatic Ach production in these subcellular fractions.

Some reports suggest that Ach may regulate the activity of brain ChAT by mass action (Potter et al, 1968; Glover and Potter, 1971). Solubilized rat brain ChAT is also capable of producing acetyl CoA and choline as products, but the Ach synthesizimg direction is favored, with an equilibrium constant of 450 (Glover and Fotter, 1971). The physiological importance of Ach inhibition of ChAT has been investigated by Harris et al (1978). These inves- 
tigators have suggested that synthesis of new Ach in vivo is inhibited by acetylcholinesterase inhibitors, which preserve released Ach, and atropine, which is beleived to bind yo presynaptic receptors, and acts to reduce the amount of Ach released. Several investigators have reported that total synaptosomal ChAT activity is not inhibited more than $50 \%$ at Ach concentrations of 100-150mM (Potter et al, 1968; Kaitia and Goldberg, 1969; Glover and Potter, 1971). Recently, Singh et al (1975) have reported the isolation of a low activity form of ChAT which is resistant to inhibition by high concentrations of Ach, which are capable of inhibiting a higher activity form to a greater degree. Therefore, the inhibition of both the solubilized and membrane bound enzyme forms by Ach was investigated in this study. The results presented in Table 3 indicate that the membrane bound enzyme form is less resistant to Ach inhibition at Ach concentrations greater than 150m than the solubilized form of ChAT.

It should be noted that exogenous Ach concentrations referred to on this experiment are extravesicular. This exogenous Ach may be separated from a fraction of the membrabe bound ChAT, thus accounting for the incomplete inhibition of total membrane bound ChAT activity. Since vesicular Ach but not cytoplasmic Ach is protected from Acgt hydrolysis, (Whittaker et al, 1964; Whittaker and Sheridan, 1965), the ability of the subcellular fractions to produce Ach at saturating levels of choline and acetyl CoA in the prescence of a 100,000 fold excess of AChE was tested. These results (see Table 4) reveal that approximately $40 \%$ of the control level of Ach was maintained in the washed crude vesicular fraction, but $97 \%$ of the Ach produced by the solubilized enzyme form was hydrolyzed. The identity 
of the product resistant to hydrolysis present in the crude vesicular fraction was found to be Ach with descenting paper chromatography. While these results may indicate that a portion of the enzyme present in the washed crude vesicular fraction is protected from the effect of an excess of Ach , it is possible that enclosed vesicles are formed during the initial homoginization of the brain minces, which may represent entrapped cytoplasmic components, including cytoplasmic ChAT. If this were occurring, the addition of an excess of AchE to the brain minces during the initial homogenization would case the incorporation of AchE into these artifactually produced vesicles, thus hydrolyzing the Ach produced by ChAT in this location. However, when this experiment was done no reduction in Ach production was found in either the combined washes of the crude vesicular fraction, representing cytoplasmic ChAT of the nerve ending, or the washed crude vesicular fraction, representing membrane and perhaps vesicular bound ChAT. However, 90\% of the ChAT activity not bound to membranes following hypo-osmotic shock of the synaptosomal subcellular fraction was inhibited. The ions $\mathrm{Na}^{+}$and $\mathrm{Cl}^{-}$have been implicated as activators of brain ChAT activity (Potter etyal, 1968; Hebb et al, 1975; Rossier, 19甲7; Hersh et al, 1978) and uptake of choline (see Kuhar and Murrin, 1977). To determinx if the membrane bound and solubilized forms of ChAT have different degrees of dependency on the prescence of $\mathrm{Na}^{+}$, both enzyme forms were incubated in lowered $\mathrm{Na}^{+}$concentrations (see Table 5*. It is apparent that both forms of ChAT are dependent on $\mathrm{Na}^{+}$, although the membrane bound form was less inhibted (62\%) than the solubilized form, which was inhibited to nondetectable levers.

Styrylpyridine analogues, such as 4-(1-nahthylvinyl)pyridine (4-NVP) are potent in vitro inhibitors of solubilized ChAT (Smith 
et al, 1967; Allen et al, 1970; Cavallito et al, 1969; Goldbeerg et al, 1971; Baker and Gibson, 1971; 1972; Krell and Goldberg, 1975). Repeatgd attempts by several investigators to administer 4-IVVE in vivo and reduce the level of brain Ach have been unsuccessful (Carson et al, 1972; Glick et al, 1973; Eaubrich et al, 1974; Krell and Goldberg, 1975). Nerve ending ChAT activity can be inhibited approximately $65 \%$ without affecting brain levels of Ach after an i.p. dose of 200 or $400 \mathrm{mg} / \mathrm{kg} 4-\mathrm{NVP}$ ( $\mathrm{Krell}$ and Goldberg, 1975), indicating that brain ChAT activity is not rate limiting. An alternative possibility is that the majority of brain Ach maybe synthesized by ChAT in a subcellular location inaccessible to the inhibitor. TO test this possibility, the solubilized and membrane bound forms of the enzyme were incubated in the prescence of varying concentrations of 4-NVF and their activities determined. The resultsa shown in Table 6 indicate that the soluble form of ChAT is more sensitive to inhibition by 4-NVP than the membrane bound form of the enzyme. 4-NVP, at a concentration of 1.2 MM, inhibits the activity of the solubilized enzyme by $65 \%$ without significantly reducing the activity of the membrane bound form. In agreement with Krell and Goldberg (1975), the $K_{i}$ of 4-NVP for the solubilized enzyme was found to be 1. OuM.

To determine if one or both enzyme forms were inhibited in vivo, mice were pretreated with either an i.p. injections of 4-NVP (200 $\mathrm{mg} / \mathrm{kg}$ ) or saline in equal volumes and then killed alternatively 30 minutes later. Both solubilized and membrane bound enzyme forms were prepared from both treated and control groups, and their respective enzyme activities determined in the prescence of a saturating choline concentration. The results shown in Table 7 indicate that i.p. administration of $200 \mathrm{mg} / \mathrm{kg} 4-\mathbb{N V P}$ inhibits the activity of the soluble, cytoplasmic form of ChAT by $77 \%$ while 
inhibiting the membrane bound form by only $29 \%$.

In the study of Krell and Goldberg (1975), it was reported that mice injected with 4-NVP appeared ataxic and depressed. This behavioral effect was observed in the present study. The effect was correlated to the locomotor activity of the mice in Fig. 3. In this experiment, 4 mice were injected with 4-NVP (200 $\mathrm{mg} / \mathrm{kg}$ ) or saline in equal volumes, or not injected, the latter group serving as an injection control. It was found that locomotor activities were rduced by approximately $80-90 \%$ with respect to either the injected or noninjected control group, and this decrease in locomotor activity was present 3 hours after a single injection. Extracellular choline is transported into synaptosomes (Yamamura and Synder, 1972; 1973; Kuhar et al, 1973; 3arker and Mittag, 1975; Carroll and Buterbaugh, 1975) and brain tissue minces (Carroll and Goldberg, 1975) by two distinct uptake mechanisms, a high affinity uptake system with a $\mathrm{K}_{t}$ of 0.5 to 5.0 un and a low affinity system with a $\mathbb{K}_{t}$ of 50 to 100uvi. Most of the choline transported into synaptosomes by high affinity transport is converted to Ach, when an AchE inhibitor is present in the incubation (Yamamura and Synder, 1972; 1973; Guyenet et al, 1973; Kuhar et al, 1973; Barker and Mitta.g, 1975).

The $\mathrm{K}_{\mathrm{m}}$ values reported for solubilized ChAT with respect to choline range from 0.1 to $0.7 \mathrm{mM}$ (see Table 8 ). All reported $\mathrm{K}_{\mathrm{m}}$ values exceed the high affinity choline transport $K_{t}$ by at least 100 fold. To determine if the $\mathbb{K}_{m}$ for membrane bound ChAT for choline might approximate that of high affinity choline transport, the choline kinetics of both solubilized and membrane bound enzyme forms were determined over a choline concentration of $4,25 \times 10^{-3} \mathrm{M}$ to $4.25 \times 10^{-7}$. The results shown in Fig. 4 suggest that membrane bound ChAT appears to have both a high affinity $\left(\mathrm{K}_{\mathrm{m}}=3.2 \mathrm{MM}\right.$ and a low 
affinity ( $\left.\mathrm{K}_{\mathrm{m}}=0.478 \mathrm{mi}\right)$ Michaelis constant, whereas the solubilized form shows only a low affinity $\mathrm{K}_{\mathrm{m}}\left(\mathrm{K}_{\mathrm{m}}=0.166 \mathrm{mI}\right)$ for choline (see Fig. 5). Hoever, the production of acetylated endogenous stores in the washed crude vesicular fraction has been shown to be approximately 14\% of the amount of Ach produced when saturating choline levels are present (see Table 9). This level of production is similar tim that determined when the membrane bound enzyme form is incubated in the prescence of $4.25 \times 10^{-6} \mathrm{M}$ or $4.25 \times 10^{-5} \mathrm{M}$ choline. The results shown in Table 10 indicate that the acetylated product present after incubation of the membrane bound enzyme form in the abscence of added choline is actually two moirties, one with an $R_{f}$ value similar to that found for acetylcarnitine. Fowever, it is beleived that carnitine is a poor substrate for brainchAT $\mathbf{Z}$ ( Bradshaw and Hemsworth, 1972).

The substate specificity of ChAT has been studied by several investigators and recently, in cat superior cervical ganglion and rat brain synaptosomes, the choline analogues triethylcholine (TEC) and homocholine have been shown to be acetyla ed (Ilson and Collier, 1975; Collier et al, 1977; Ilson et al, 1977). zTherefore, the abdlity of the membrane bound form of ChAT to acetylate these analogues was tested (see Figs. 6 and 7). In this study, both solubilized and membrane bound forms of ChAT weew incubated at varying time intervals in the prescence of $4.25 \times 10^{-2} \mathrm{M} \mathrm{TEC}$ and $1.0 \times 10^{-2} \mathrm{M}$ homocholine. Under these conditions, it was suggested that TEC was acetylated by the membrane bound form of ChAT at 5,155 30, and

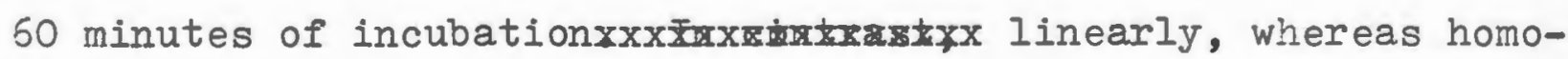
choline was also apparently acetylated by the momorane bound form a.t $5,15,30$, and 60 minutes of incubation. In contrast, the solubilized enzyme form was less able to acetylate TEC than the membrane bound form, and homocholine was not acetylated by the solu- 
bilized enzyme at 30 minutes of incubation, even in the prescence of a 5 fold excess of the solubilized enzyme form kdata not shown). The identification of these acetylate d choline analogues wa.s performe on descending paper chromatography, and $R_{f}$ values were obtained (see Table 10). These results imply that the acetylated product(s) formed from both TEC and homocholine incubations are different from the value reported for Ach, but their identtities with respect to the acetylated product(s) obtained during incubations performed in the abscence of choline are less cleas. In fact, the $R_{f}$ values reported for acetylated TEC and homocholine, which agree with those reported by IIson et al (1977) and Collier et al, (1977), are similar to a $R_{f}$ value obtained after incubation in the abscence of added choline. Therefore, the identification of the acetylated choline analogues TEC and homocholine by mouse brain membrane bound ChAT remains unconfirmed.

\section{DISCUSSION}

Theenzyme that synthesizes Ach, ChAT, is localized in cholinergic nerve terminals, and the majority of the enzyme is beleived to be soluble, and Ach synthesis is beleived to occur in the cytoplasm of the nerve ending (Fonnum, 1967; 1968; 1975). Following cytoplasmic synthesis, Ach is then beleived to be trans fered into synaptic vesicles (Fonnum, 1975). However, the transfer of Ach into synaptic vesicles above diffusion levels has not been demonstrated (Katz et al, 1973; Suszkiw, 1976). Additionally, the vesicular emptying of Ach appears to facilitate the transport of extracellular choline but not Ach into vesicles independently of the cytoplasm, suggesting that maintenance of vesicular stores may not be dependent on cytoplasmic synthesis and transfer of Ach into vesicles (Carroll and Nelson, 1978). 
Enzyme forms with different surface charges (Fonnum and MaltheSorensson, 1972), types of antibodies produced (Singh et al, 1975) and Ach inhibition characteristics (Bingh et al, 1975) from the same enzyme source. Furthermore, the cytochemical studies of Feigenson and Barrnett (1977), Bene and Barrnett (1978) and Hattori et al (1976) have indicated that at least some of the nerve ending ChAT is associated with vesicular membranes.

Results obtained in this investigatio indicate that a membrane bound form of ChAT can synthesize Ach, and has properties beleived to be characteristic of enzymes on membranes, including altered enzyme kinetics, inhibition susceptibilities, and substrate specificities, than the enzyme off the membrase (Hochstadt abd Quinlan, 1975). Other results obtainedinthis study suggest that some of the membrane bound ChAT is located in a position which allows some Ach to be synthesized and protected from Ache hydrolysis and allows some ChAT to be active in the prescence of high exogenous Ach concentrations.

4-NVP is a reversible, specific inhibitor of solubilized ChAT (Smith et al, 1967; Cavallito et al, 1969; Goldberg et a.1, 1971; Kre 1 and Goldberg, 1975). In the present experiments, 4-NVP inhibited the solubilized form of ChAT to a greater extent than membrane bound ChAT in both invitro and in vivo studies.

It has beensuggested that brain ChAT is present in excess and is not rate limiting, since a $65 \%$ inhibition of synaptosomal ChAT can be inhibited by 4-NVP with no effect on brain Ach levels (Krell and Goldberg, 1975) and 4-NVP has no effect on cholinergic transmission (Aquilonius et al, 1970). Another interpretation is that solubilized ChAT may be present in a location susceptible to4-IVVP, whereas membrane bound ChAT is relatively inaccessible to 4-NVP inhibtion, and may maintain vesicular Ach stores. Furthermore, 
Barker (1973) has shown that 4-NVP treatment inhibits the low affinity uptake of choline, which is not beleived to be responsible for providing choline for acetylation and Ach production, and has only a neglible effect on high affinity choline uptake, which is beleived to provide choline almost exclusively for Ach synthesis (see Freeman and Jenden, 1976).

The regulation of ChAT by Ach product inhibition has been suggested by several investigators (Potter et al, 1968; Kaita and Goldberg, 1969; Glover and Potter, 1971), but it is only able to inhibit synaptosomal ChAT by $50 \%$ at Ach concentrations of $100 \mathrm{mM}$ or more. Therefore, for Ach to act as ac physiological inhibitor of ChAT, the enzyme must be exposed to higher concentrations than are beleived to be present in the nerve terminal cytoplasm. On the other hand, the intravesicular concentration ofAch has been estimated to be at least 200mM (Barkeret al, 1970). It has been reported that one form of ChAT is able to be inhibited by phsyiological concentrations of Ach, whereas a low afimix activity form of ChAT (analogous to the membrane bound form of ChAT) is not profoundly inhibited by those levels of Ach. This investigation indicates that the membrane bound form of ChAT may reach maximal inhibition at an extravesicular concentration of 150min, while the solubilized form of ChAT can be completely inhibited by Ack.

It has been proposed that high affinity choline uptake regulates Ach synthesis (MacIntosh and Collier, 1976; Eaubrich and Chippendale, 1977). Barker and Mittag (1975) and Iefresne et al (1973) have propsed that high affinity choline transport and Ach synthesis are coupled processes. However, Barker (1978) has found that a Compound (TMPYA : N,N,N-trimethyl-N-propylnyl-ammonium) can be taken up by the high affinity transport system and not be acetylated, and 
Iope and Jenden (1977) have found that conditions which compromise the availability of acetyl COA lead to a drop in Ach synthesis without impairing high affinity uptake. In this investigation, it was found that the degree of inhibition of the membrane bound form of ChAT by a lowered sodium concentration corresponds well with the degree of sodium dependency ascribed to the high affinity choline transport system in synaptosomes (Simon and Kuhar, 1976), suggesting that the sodium requirement of the membrane bound form of ChAT

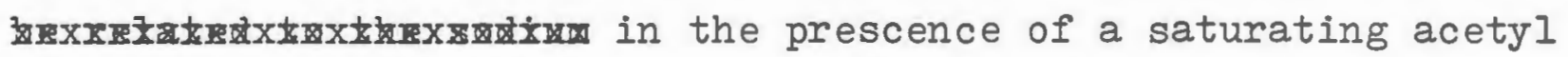
CoA concentration may be related to the sodium reqiurement of the high affinity choline transport system.

The choline kinetics determinations on the enzyme forms, done without correction for endogenous acetylation, indicate that the membrane bound enzyme might have a high affinity component for

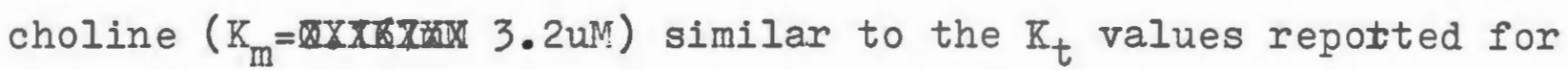
high affinity choline transport. However, after correction for endogenous choline acetylation is performed, the choline Michaelis constants obtained for both solubilized and membrane bound ChAT are similar ( $\mathrm{K}_{\mathrm{m}}=0.167 \mathrm{mM}$ and $0.478 \mathrm{mM}$, respectively), a result which agrees with that reported by Kucenski et al (1975).

Recently, it has been discovered that triethylcholine and homocholine can be acetylated by the cat superior cervical ganglion during electrical stimulation to a greater extent than by in vitro tests, which use solubilized ChAT preparations (Femsworth and Smith, 1970; Currie and Mautner, 1974; Ilson and Collier, 1975; Collier et al, 1977; Ilson et al, 1977). Furthermore, it has been found that homocholine can be acetylated by a synaptosomal preparation of rat brain ChAT after a 5 minute incubation (Collier et al, 1977), and that, while homocholine can be transported by the high affinity uptake system, not all the homocholine transported during (Collier 
et al, 1977) or subsequent to stimulation (Carroll and Nelson, 1979) is acetylated. These latter ressults may suggest that acetylation rather than high affinity uptake is rate limiting. In this investigation, it was found that triethylcholine could be acetylated by both the solubilized and membrane bound ChAT at a concentration of $4.25 \times 10^{-2} \mathbb{M}$, incubated for $30 \mathrm{~min}$ utes at $39 \mathrm{C}$. The $\mathrm{R}_{f}$ value obtained for the acetylated product on descending paper chromatography correspond to that value ob-

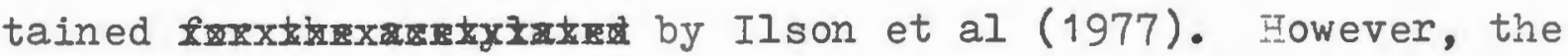
apparent acetylation of homocholine by membrane bound ChAT appears to be similar to endogenous acetylation at 60 minutes of incubation, but not at 5 or 15 minutes. Furthermore, the acetylated compound(s) present after incubation in the abscence of added Ccholine for 60 minutes have identical $R_{f}$ values, agreeing with those reported by Collier et al (1977) for acetylated homocholine.

In conclusion, it appears that some nerve ending ChAT present in hypo-osmotically shocked synaptosomes is not solubilized by high ionic strength washes, and may be nonionically assoctated with synaptosomal membranes, including vesiculat membranes. This membrane bound form of ChAT possess a similar affinity for its substrate choline as the solubilized enzyme, but only after the former is corrected for endogenous acetylation. Furthermore, membrane bound ChAT is less sensitive to inhibition caused by 4NVP, Ach, reduced sodium levels, and hydrolysis of Ach formed than the solubilized form of mouse brain ChAT. 
TABIE 1

Reported $\mathrm{K}_{\mathrm{m}}$ values for brain choline-o-acetyltransferase (ChAT)

\begin{tabular}{|c|c|c|c|}
\hline Tissue source & $I_{m}$ (choline) & \multicolumn{2}{|c|}{$K_{m}(\operatorname{acety} 1 \mathrm{COA})$} \\
\hline rat brain & $184 \mathrm{uM}$ & 13. OuM & $\begin{array}{c}\text { Kucenski et al } \\
\left(\begin{array}{l}(8 \% \% \\
1975)\end{array}\right.\end{array}$ \\
\hline human putamen & $510 u \mathrm{M}$ & 11. Oum & $\begin{array}{l}\text { White and Wu, } \\
\qquad(1973)\end{array}$ \\
\hline human caudate & $600 u \mathrm{M}$ & $6.6 \mathrm{um}$ & $"$ \\
\hline rat brain & $410 u \mathrm{~N}$ & 18. Our: & $"$ \\
\hline rabbit brain & $640 \mathrm{um}$ & 11. OuM & $"$ \\
\hline bovine striatum & $750 u M$ & 10. OuM & $\begin{array}{l}\text { (lover and Potter, } \\
(1971)\end{array}$ \\
\hline bovine caudate & $800 u \mathrm{M}$ & 16. Ourn & $\begin{array}{l}\text { White and Cavallito, } \\
\qquad(1970)\end{array}$ \\
\hline mouse brain & $700 \mathrm{uM}$ & 17, OuM & $\begin{array}{l}\text { Kaita and Goldberg, } \\
(1969)\end{array}$ \\
\hline
\end{tabular}


TABLS 2

The Recovery and Distribution of Synaptosomal Cholino-0-Acetyltrancfernes (ChMT) and protein

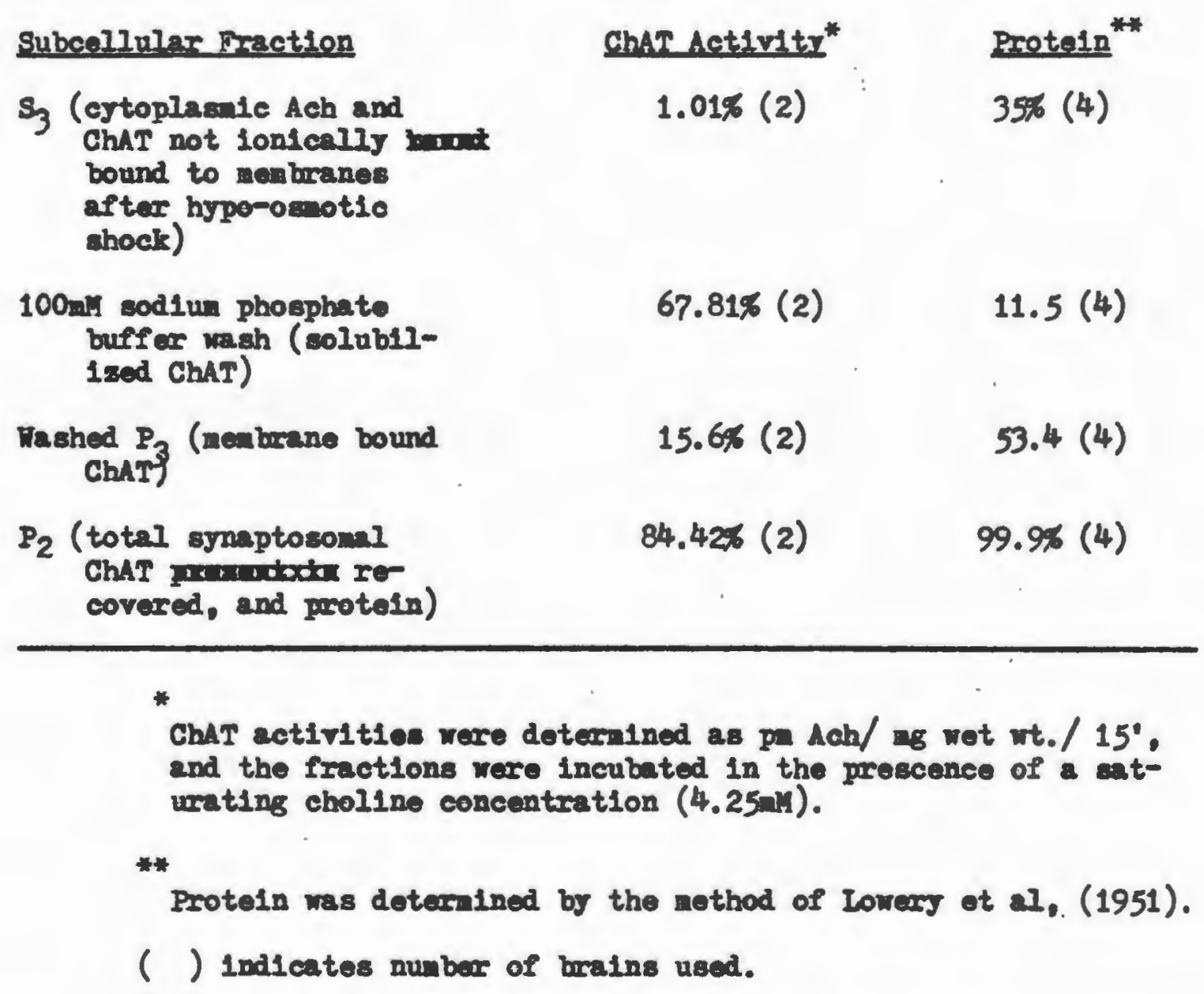




\section{TABIE 3}

Inhibition of Solubilized and hembrane Bound Choline-

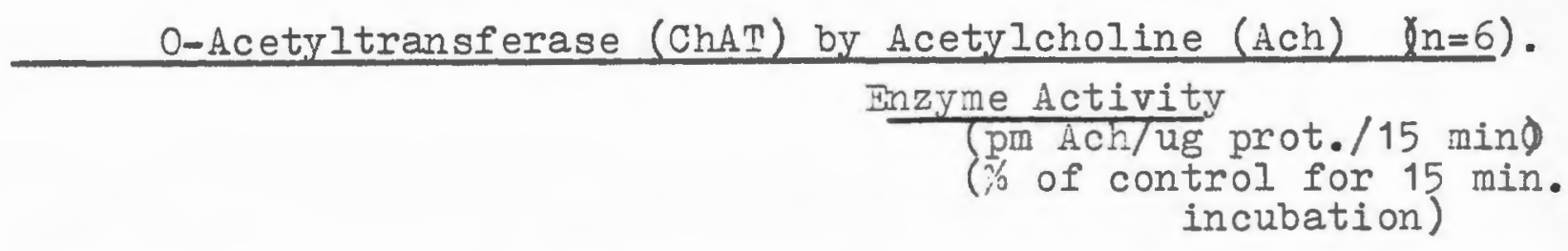

$\frac{\operatorname{Ach}(\mathrm{mil})}{0(\text { control })}$
10
50
100
150
200
383

Membrane Bound ChAT

$$
\begin{aligned}
& 100 \pm 6.5 \\
& 116.2 \pm 9.8 \\
& 77.7 \pm 8.7^{*} \\
& 52.8 \pm 4.3^{*} \\
& 31.0 \pm 2.9^{*} \\
& 30.4 \pm 3.9^{*} \\
& 26.7 \pm 3.6^{*}
\end{aligned}
$$

Enzyme forms were prepared from mouse brain minces incubated in $35 \mathrm{mMZ}^{+} \mathrm{Krebs}$ medium for 4 minutes at $37 \mathrm{C}$. The inhibitory concentrations of Ach are exclusively extravesicular.

${ }^{*}$ Results significantly differ from control ( $p$ 0.05) 
TABIE 4

Determination of Choline=0-Acetyltransferase (6hAT) Activity in Subcellulat Fractions of Mouse Forebrain in the Prescence and Abscence of an Excess of Acetylcholinesterase (AchE) ( $n=7)$.

\section{Subcellular Fractions}

100mM Sodium

Phosphate

Buffer Wash

Control*

\begin{tabular}{cc}
$\frac{\text { of } P_{3}}{129.8 \pm 20.6}$ & Washed $P_{3}$ \\
$3.9 \pm 2.6$ & $1.6 \pm 0.4$ \\
\hline 3.9
\end{tabular}

* Chat activity expressed as pm Ach/ug prot./5 min. **

mough Eel AchE was added to the incubation medium to hydrolyze 2.84umoles of Ach to cholie per min. This amount represents an excess of at least 100,000 fold. 
TABLE 5

The Effect of Lowered Sodium ion concentration on Choline-0-Acetyltransferase (ChAT) in Subcellular Fractions of Mouse Brain

\begin{tabular}{|c|c|c|}
\hline \multirow[b]{2}{*}{ Subcellular Fraction } & \multicolumn{2}{|c|}{ ChAT Activity (pm Ach/ mg wet wt $/ 5$} \\
\hline & $\begin{array}{l}318 \mathrm{mM} \mathrm{Na}^{+} \\
(\text {Control) } \\
\end{array}$ & $\begin{array}{l}236.3 \mathrm{mM} \mathrm{Na}^{+} \\
\text {(Lowered } \mathrm{Na}^{+} \text {) }\end{array}$ \\
\hline washed $P_{3}$ & $89.8 \pm 8.7(5)$ & $34.35 \pm 4.9(5) *$ \\
\hline $\begin{array}{l}\text { pooled 100mM } \\
\text { sodium phosphate } \\
\text { buffer washes }\end{array}$ & $180.1 \pm 25.5(5)$ & not detectable $(5)^{*}$ \\
\hline
\end{tabular}


TABII 6

In vitro Inhibition of Solubilized and Membrane Bound Forms of Choline-0-Acetylttansferase (ChAT) by 4-(1naphthylvinyl) pyridine (4-IVF) ( $n=7)$.

Enzyme Activity

(pm Ach/ug prot./ $5 \mathrm{~min}$ )

4-INVE (UM)

0 (control)

0.072

0.290

1.16

4.63
Solubilized ChAT Membrane 3ound ChAT

$88.0 \pm 16.8$

$7.56 \pm 0.43$

$74.2 \pm 12.08$

$7.69+0.41$

$70.3 \pm 12.0$

$7.34 \pm 0.46$

$32.2 \pm 7.8^{*}$

$6.94 \pm 0.34$

$12.4 \pm 6.1^{*}$

$5.29 \pm 0.33^{*}$

* Results significantly different from control ( $p$ 0.05). 
TAEIE 7

In vivo Inhibition of solubilized and Hembrane Dound Forms of Choline-0-Acetyltransferase (ChAT) by 4-(1naphthy lvinyl) pyridine (4-ivp)

Enzyme Activity

(pm Ach/ug prot./ 5 min.)

(\% of control for 5 min incubation)

Treatment ${ }^{*}$

Control

4-iv

\section{Solubilized ChAT} $100 \pm 10(7)$ $23 \pm 10^{*}(8)$
Nembrane Bound CDAT $100 \pm 19$

* Mice were injected with $200 \mathrm{mg} / \mathrm{kg} 4-\mathrm{NVP}$ i.p. or an equal volume of saline 30 minutes prior to cervical dislocation. Tnzyme forms were prepared from mouse brain minces incubated in $35 \mathrm{mmK}^{+} \mathrm{Krebs}$ medium. ( ) indicates the number of brains used.

** Results significantly different from control (p 0.05) 
TAPLE 8

Comparison of Membrane Bound Enzyme Activities in the Prescence of Various Choline Concentrations $(n=8)$.

choline (Molar)

Membrane Bound ChAT Axtivity

$4,25 \times 10^{-3}$

$$
68.3 \pm 9.3
$$

$4.25 \times 10^{-7}$

$7.84 \pm 0.4^{*}$

0 (no added choline)

$9.35 \pm 0.5$

* Result significantly lower than value obtained in the abscence of added choline. ( $p$ 0.05) 
TA3L 9

Apparent $R_{f}$ values of the acetylated products obtained by paper chromatography with various substrates from mouse brain minces

Substrate

choline $(4.25 \mathrm{mM})$

triethylcholine $(42.5 \mathrm{mIl})$

homocholine (10.0mM)

no added substrate
$R_{f}$ value of acetylated compound synthesized by the subcellular fraction th question

\begin{tabular}{|c|c|c|}
\hline & $\begin{array}{l}\text { 100mM } \\
\text { sodium } \\
\text { phosphate } \\
\text { buffer } \\
\text { wash }\end{array}$ & washed $\underline{D}_{3}$ \\
\hline choline $\left(4.25 \mathrm{mM}^{2}\right)$ & 0.30 & 0.30 \\
\hline triethylcholine (42.5mMd) & $0.92^{*}$ & $0.90^{*}$ \\
\hline homocholine (10.0m & $0.74^{* *}$ & $0.80^{* *}$ \\
\hline no added substrate & $0.30 \& 0.74$ & $0.30 \approx 0.80$ \\
\hline
\end{tabular}

Descending paper chromatography was performed on

Whatman No. 1 paper in a solvent system of n-butanolacetic acid- water $(8: 2: 3: 1)$. Incubations were done at room temperature for 8 hours. ${ }^{*} R_{f}$ values agree with those of Ilson et al (1977). $R_{f}$ values agree with those of Collier et al (1977). 
FIg. 1

Subcellular Fractination and Engyno Proparation

MOUSE BRAIN MINCES

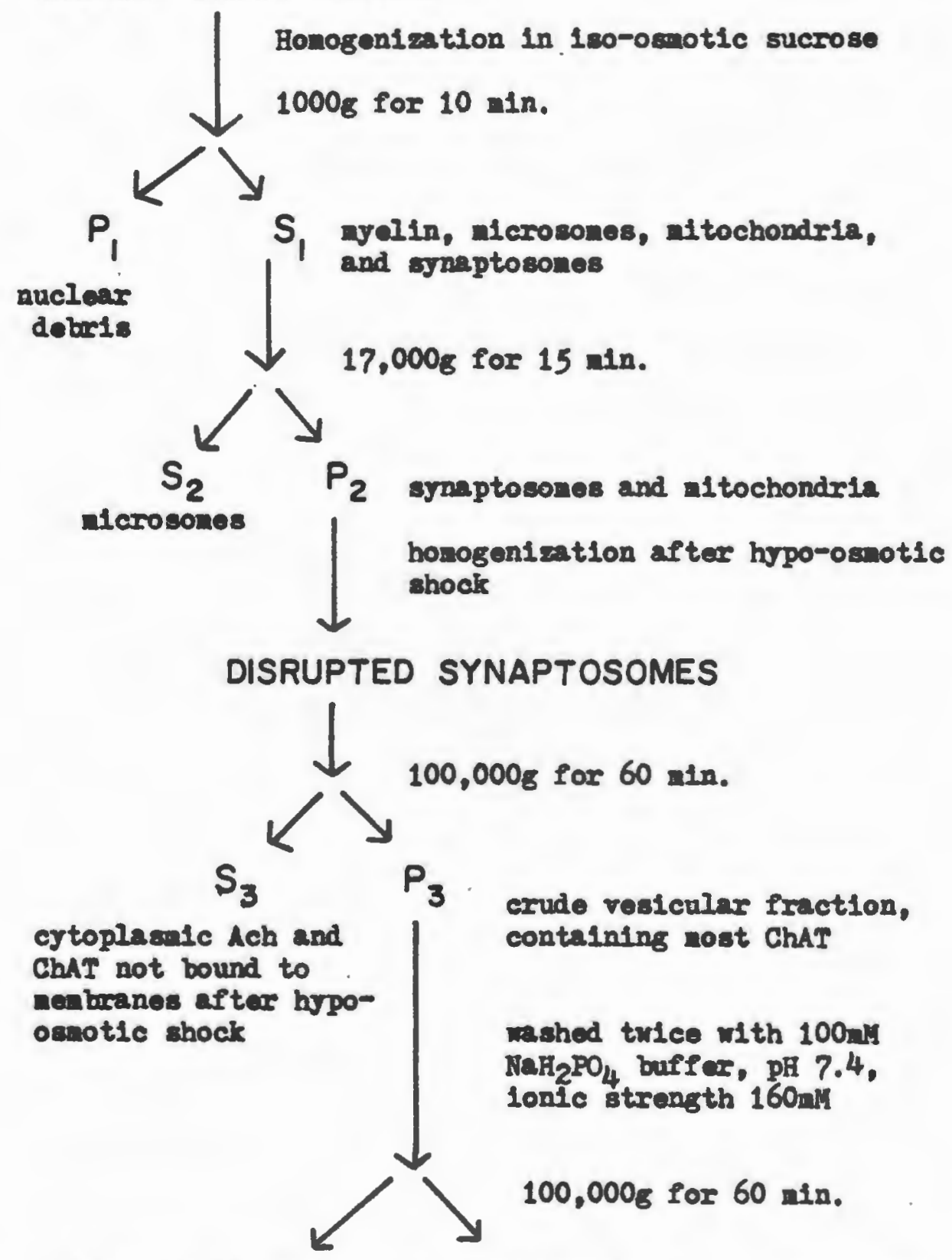

COMBINED $\mathrm{NaH}_{2} \mathrm{PO}_{4}$ WASHED $P_{3}$ contalning BUFFER WASHES menbrane bound ChAT containing ertoplasic Chat 
F16. 2 Acetylation of Choline by Membere Bound and Solubilised Forms of Chat ( $\square$ and

b. respectively) over tine. Bnzyne activities expressed as pi Aoh/ug prot./tino $(n-9)$.

SOLUBILIZED

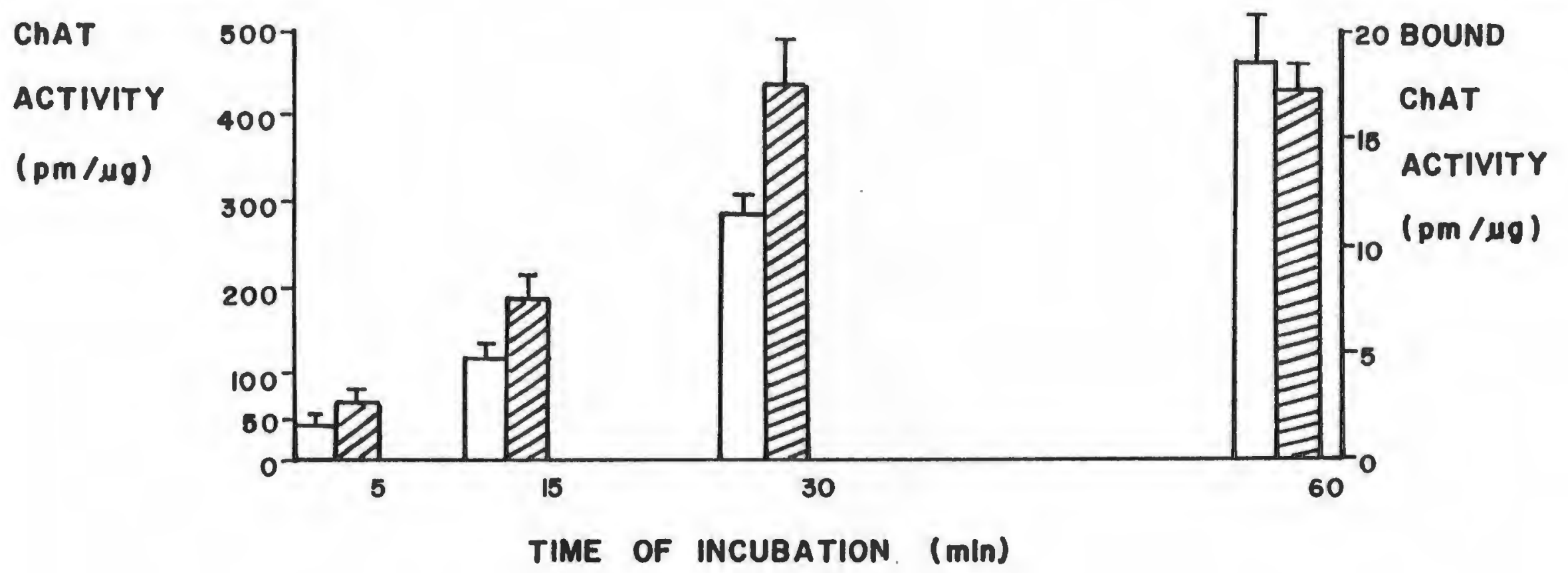


F18. 3

Effect of 4-(1-mephthylvinyl)psridine (4-IVP) on Mouse Loconotor Activity

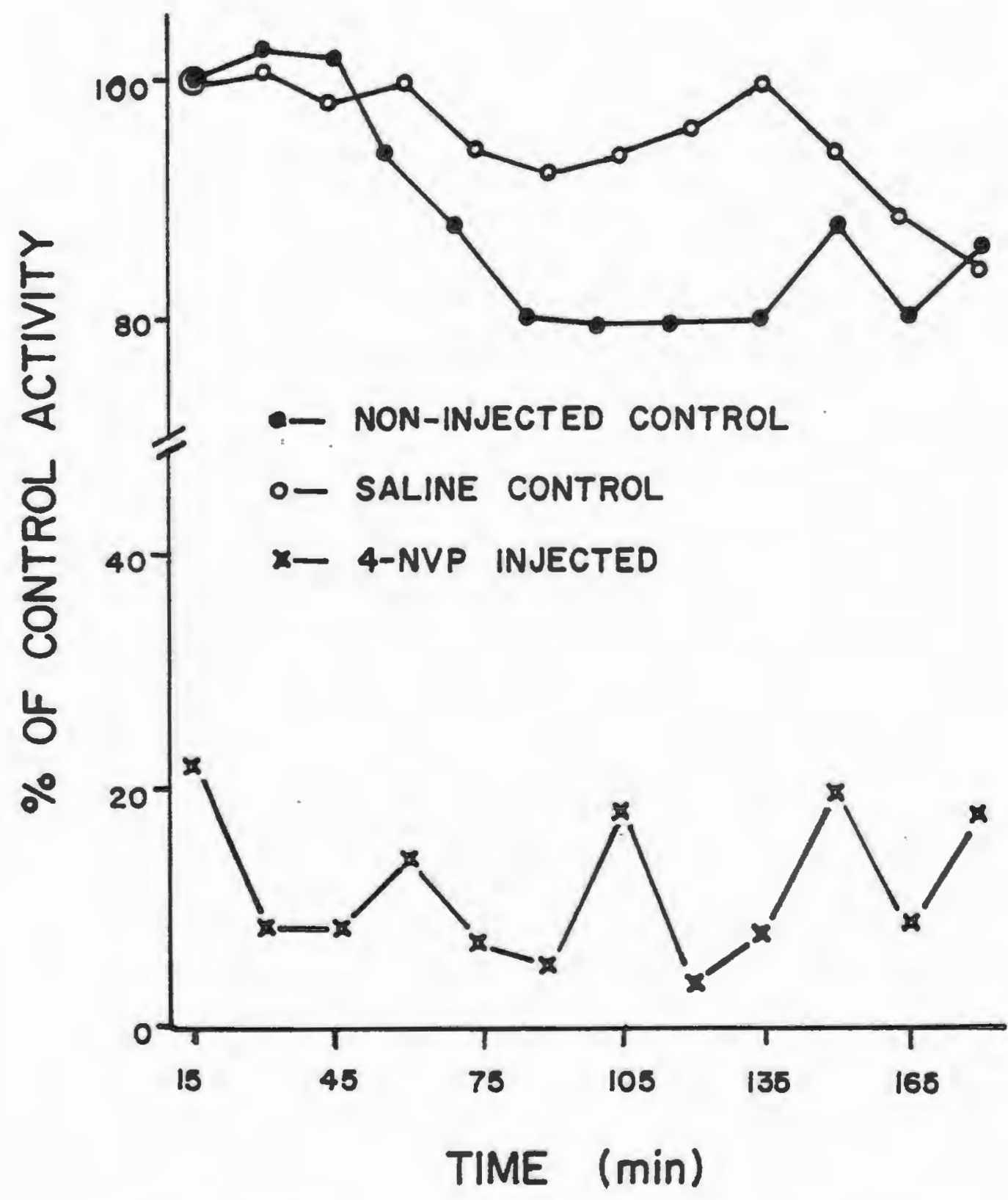

4 nice were injected 1.p. with $200 \mathrm{mg} / \mathrm{kg} 4-\mathrm{rVP}$ or an equal volune of aline, or not injected. Ioconotor activities were doternined for a group of 4 alce in actirits chanbars equipped with Selective lctivity Moter - Model $S$ at 15 minute Intervals. Bach point represents the arerage of 2 deterninations. 
F16. 4 Choline K1neties of the Menbrane Bound Entyme Form, corrected (--) and uncorrected (- - ) for andogenous acotyintion

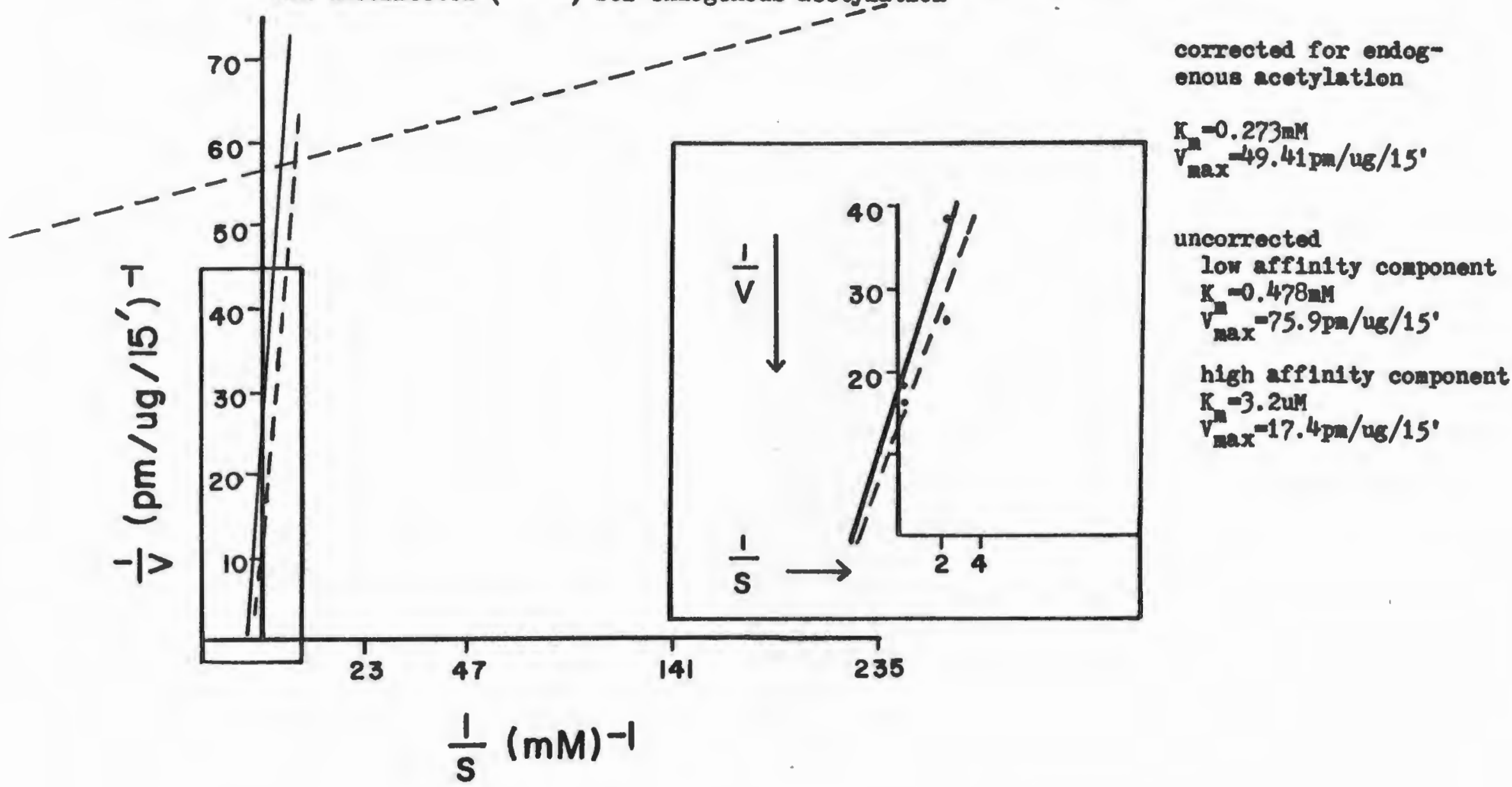


Fig. 5 Choline Kinetics of the Solubilised Fnzyre Form, corrected (-) and uncorrected (- - ), for ondogenous aootylation.

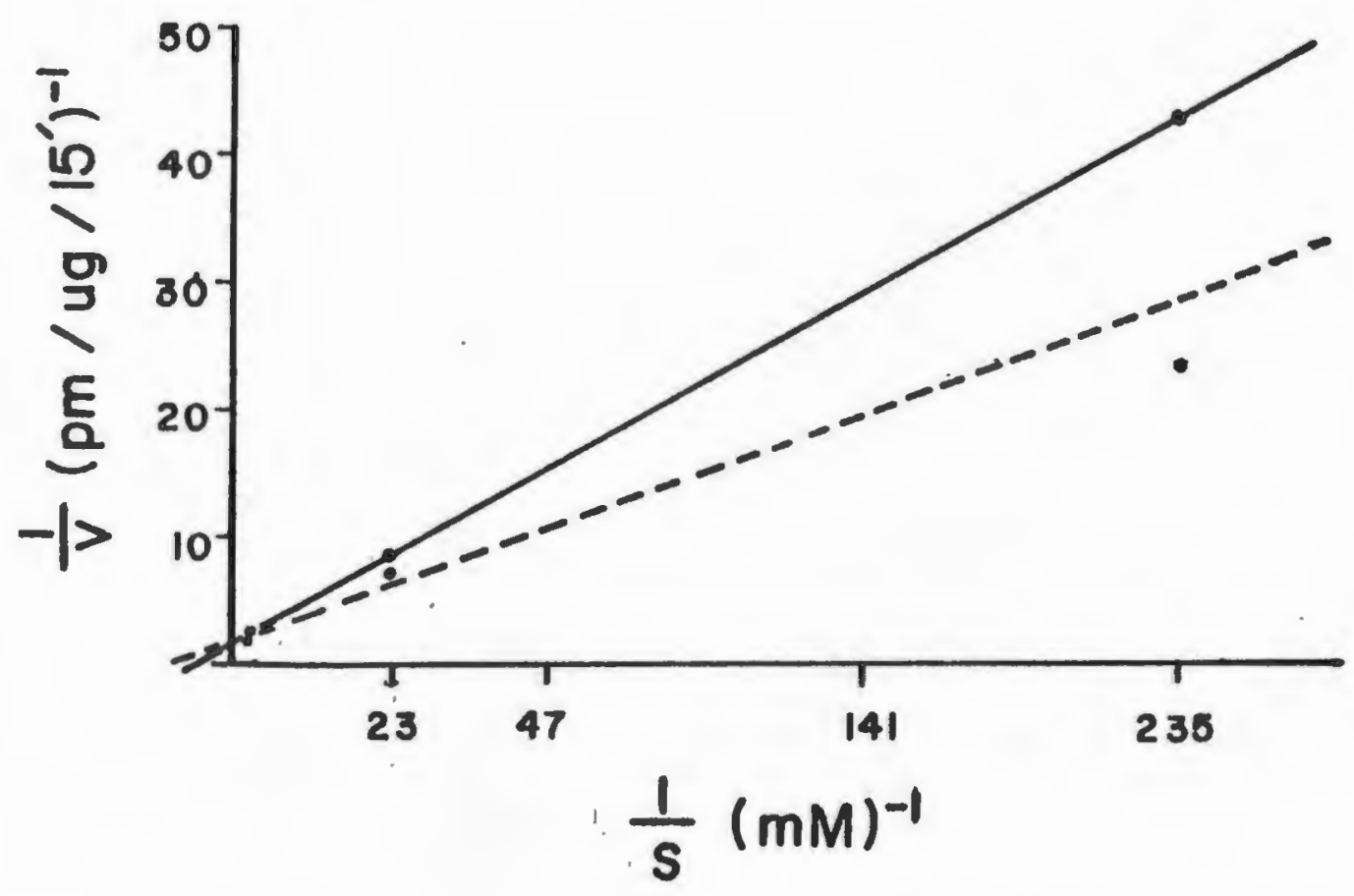

corrected for endogonous acetyletion

$K_{-}=0.189$ ar

$v_{\max }=794.9 \mathrm{pm} / \mathrm{ur}_{\mathrm{s}} / 15^{\circ}$

uncorrectid

$K_{n}-0.166 \mathrm{aM}$

$v_{\operatorname{mx}}-802.6 \mathrm{pm} / \mathrm{ug} / 15^{\prime}$ 
F16. 6 Acetylation of Bxogenous Triethylcholine (TEC) (D), Honocholine (অ), and Indogenous Substanto(a) (ㅁ) over time by Membrano Bound ChAT

( ) Indicates number of brains used.

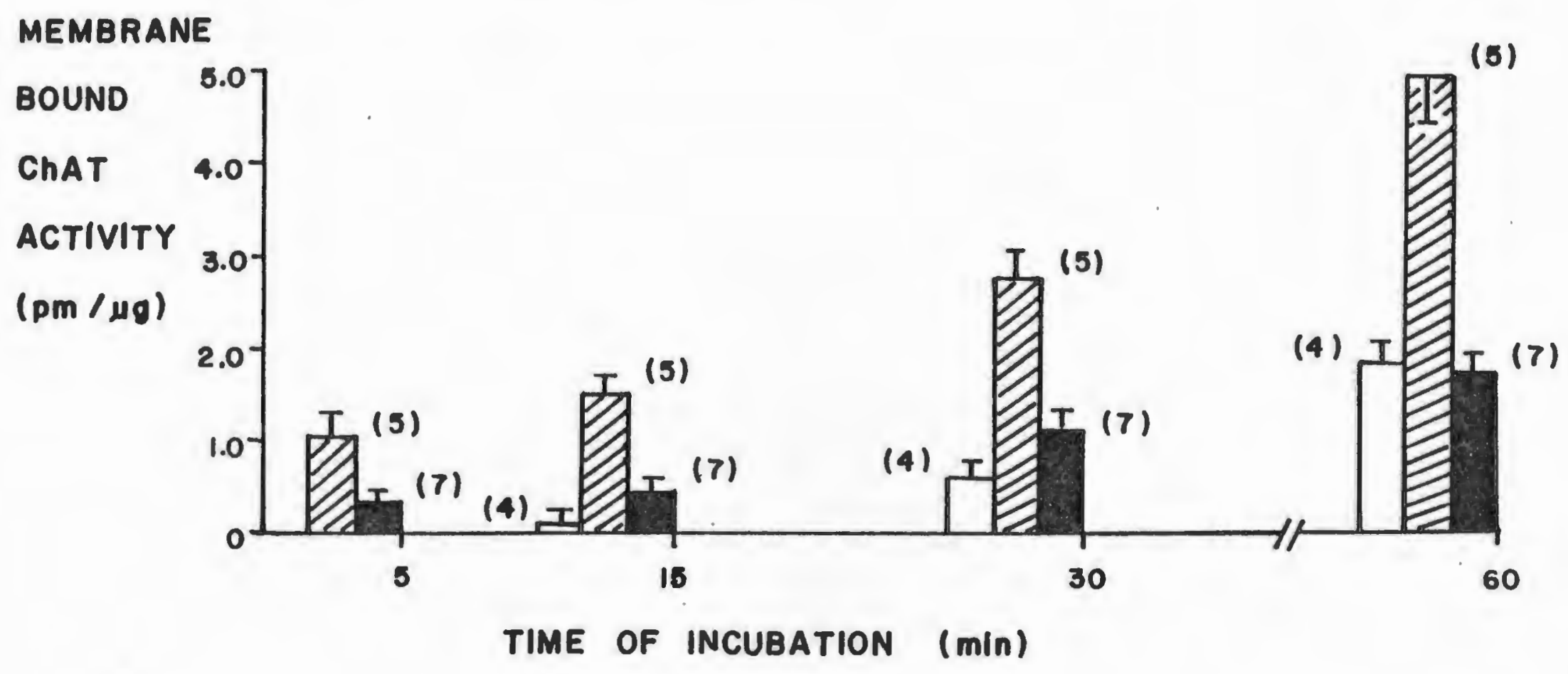


F1g. 7 Acetylation of Exogenous Triethylcholine (TE) (D), Honocholine (D), and Indogenous Substrate(s) (口) over t1me by solubilised ChAT

( ) indicates number of brains used.

\section{SOLUBILIZED}

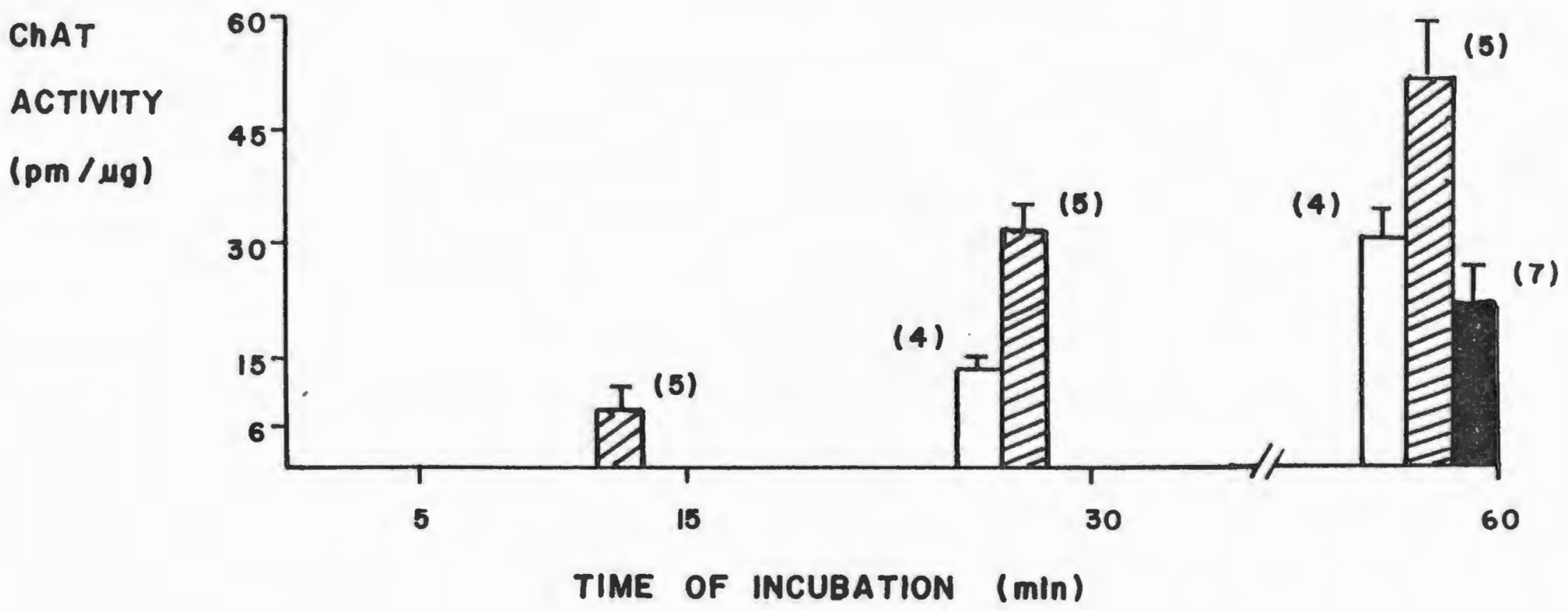




\section{REFERENCES}

Abdel-Latif, A.A. and Smith, J.E.: In vivo incorporation of choline, glycerol and orthophosphate into lecithin and other phospholipids of subcellular fractions of rat cerebrum. Biochim. Biophys. Acta 218:134-140, 1970.

Akert, K., Moor, H., Pfenninger,K. and Sandis, C.: Contributions of new impregnation methods and freeze etching to the problems of synaptic fine structure. Prog. Brain. Res. 31:223-240, 1969 .

Akert, K.: Dynamic aspects of synaptic ultrastructure. Brain Res. 49:511-518, 1973.

Akert, K. and Peper, K.: In Golgi Centennial Symposium, ed Santini, M. New York: Raven Press, pp 521-527, 1975.

Allen, R.C., Carlson, G.L. and Cavallito, C.J.: Choline acetyltransferase inhibitors. Physicochemical propérties in relation to inhibitory activity of the styrylpyridine analogues. J. Med. Chem. 13:909-912, 1970 .

Ansell, G.B. and Spanner, S.: The metabolism of [Me- ${ }^{14} \mathrm{C}$ ]choline in the brain of the rat in vivo. Biochem. J. $110: 201-206,1968$.

Ansell, G.B. and Spanner,.S.: Studies on the origin of choline in the brain of the rat. Biochem. J. 122:74-750, 1971.

Ansell, G.B. and Spanner, S.: In Cholinergic Mechanisms, ed. Wasen, P. New York: Raven Press, pp 117-130, 1975.

Aquilonius, S.M. , Frankenberg, L., Lundholm, B., Stansio, K.E. and windblagh, V.: some effects of a choline acetyltransferase inhibitor. Acta Pharmacol. Toxicol. $28: 34,1970$.

Aquilonius, S.M., Flentge, F., Schuberth, J., Sparf, B., and Sundwall, A.: Synthesis of acetylcholine in different compartments of brain nerve.terminals in vivo as studied by the incorporation of choline from plasma and the effect of pentobarbital on this process. J. Neurochem. 20:1509-1521, 1973.

Aquilonius, S.M. and Eckernas, S.A. Choline acetyltransferase in human cerebrospinal fluid: nonenzymatically and enzymatically catalyzed acetylcholine synthesis. J. Neuro. Chem. 27:317-318, 1976 . 
Atterwill, C.K. and Prince, A.K.: Multiple forms of choline acetyltransferase and the high affinity uptake of choline in brain of developing and adult rats. J. Neurochem. 31:719-725, 1978 .

Atweh, S., Simon, J.R., and Kuhar, M.: Utilization of sodium dependent high affinity choline uptake in vitro as a measure of the activity of cholinergic neurons in vivo. Life Sci. 17:1535-1544, 1976.

Baker, B.R. and Gibson, R.E.: Inhibition of choline acetyltransferase by dèrivatives of 4-stilbazole. J. Med. Chem. $14: 315-322$, 1971 .

Baker, B.R. and Gibson, R.E.: Inhibition of choline acetyltransferase. Mode of binding of 4-stilbazoles. J. Med. Chem. 15:639-642, 1972 .

Banks, P., Major, D. and Tomlinson, D.R.: Further evidence for the involvement of microtubules in the intra-axonal movement of noradrenaline storage granules. J. Physiol. $219: 755-761,1971$.

Bannister, J. and Scrase, M.: Acetylcholine synthesis in normal and denervated sympathetic ganglia of the cat. J. Physiol. 111:437-444, 1970 .

Banns, H.E.: A study of the molecular sites and stability of choline acetyltransferase. J. Neurochem. 26:967$971,1976$.

Barker, P.J., Fincham, N.J. and Hardwick, D.C.: The availability of carnitine acetyltransferase in mitochondria from guinea pig liver and other tissues. Biochem. J. $110: 739-746,1968$.

Barker, L.A., Dowdall, M.J., Essman, W.B. and Whittaker, V.P.: The compartmentation of acetylcholine in cholinergic nerve terminals. In Drügs and Cholinergic Mechanisms in the CNS, eds. Heilbronn, E. and Winter, A. Stockholm: Almqvist and Wiksell, pp 193-223, 1970.

Barker, L.A., Dowdall, M.J. and Whittaker, V.P.: Choline metabolism in the cerebral cortex of guinea pigs. Biochem. J. 130:1063-1080, 1972 .

Barker, L.A. and Mittag, T.W.: Inhibition of synaptosomal choline uptake by naphthylvinylpyridiniums. FEBS Letters, 35:141-144, 1973.

Barker, L.A. and Mittag, T.W.: Comparative studies of substrates and inhibitors of choline transport and choline acetyltransferase. J. Pharmacol. Exp. Ther. 192 : 86-94, 1975. 
Barker, L.A.: Subcellular aspects of acetylcholine metabolism. In Biology of Cholinergic Function, eds. Goldberg, A.M. and Hanin, I. New York: Raven Press, pp 203-238, 1976.

Barker, L.A.: Synaptosomal uptake of $\left[{ }^{3} \mathrm{H}-\mathrm{N}-\mathrm{Me}\right]-\mathrm{N}, \mathrm{N}, \mathrm{N},-$ trimethyl-N-propylnylammoni um (TMPYA). Fed. Proc. 37: 649,1978 .

Benes, F.M. and Bannett, R.J.: Biochemical and morphometric studies of the relationship of acetylcholine synthesis and vesicle numbers after stimulation of frog neuromuscular junctions: the effect of a choline-o-acetyltransferase inhibitor. Brain Res. 150:277-293, 1978.

Berman-Reisborg, R.: Properties and biological significance of choline acetylase. Yale J. Biol. Med. 29:403-435, 1957.

Bigalke, H. and Dimpfel, W.: Kinetics of ${ }^{3} \mathrm{H}$ acetylcholine synthesis and release in primary cell cultures from mammalian CNS. J. Neurochem. 30:871-879, 1978.

Bloom, F.E. and Aghajanian, G.K.: Cytochemistry of synapses: A selective staining method of electron microscopy. Science 154:1575-1577, 1966.

Bowers, B.: Coated vesicles in the pericardial cells of the aphid (Myzus persica sulz). Protoplasma 59:351-367, 1964 .

Bowman, W.C. and Hemsworth, B.A.: Effects of triethylcholine on the output of acetyl choline from the isolated diaphragm of the rat. Br. J. Pharmac. Chemother. 24 : $110-118,1965$.

Bowman, W.C. and Rand, M.J.: Actions of triethylcholine on neuromuscular junction. Br. J. Pharmacol. 17:176-195, 1961 .

Boyne, A.F.: Neurosecretion:integration of recent findings into the vesicle hypothesis. Life Sci. 22:2057-2066, 1978 .

Bradshaw, D. and Hemsworth, B.A.: The acetylating enzymes of rat brain homogenates. J. Pharm. Pharmacol. 28: $12,1976$.

Browning, E.T. and Schulman, M.P.: ${ }^{14} \mathrm{C}$ acetylcholine synthesis by cortex slices of rat brain. J. Neurochem. 15:1391-1405, 1968 .

Bulbring, E., Burn, J.H. and Shelley, H.J.: Acetylcholine and ciliary movement in the gill plates of Mytilus edulis. Proc. Roy. Sco. 141:455-466, 1953. 
Bull, G., Hebb, C. and Ratkovic, D.: Choline acetyltransferase activity of human tissue during development and at maturity. J. Neurochem. 17:1505-1516, 1970 .

Burt, A.M. and Silver, A.: DFP as a prerequisite in the histochemical demonstration of choline acetyltransferase. Brain Res. $57: 518-521,1973$.

Carroll, P.T. and Buterbaugh, G.G.: Regional differences in high affinity choline transport velocity in guinea pig brain. J. Neurochem. 24:229-232, 1975.

Carroll, P.T. and Goldberg, A.M.: Relative importance of choline transport to spontaneous and potassium depolarized release of ACh. J. Neurochem. 25:523-527, 1975.

Carroll, P.T: and Goldberg, A.M.: The subcellular location of $\mathrm{Ca}+2$ dependent and independent $\mathrm{ACh}$ release. 6 th Ann. Soc. Neurosci. 2:991,:1976.

Carroll, P.T. and Nelson, S.H.: Cholinergic vesicles: ability to empty and refill independently of cytoplasmic acetylcholine. Science 199:85-86, 1978 .

Carson, V.G., Jenden, D.J., and Cho, A.K.: The in vivo effects of some in vitro choline acetyl transferase inhibitors. Proc. West. Pharmacol. Sco. 15:127-131, 1972.

Cavallito, G.J., Yun, H.S., Smith, C.J., and Foldes, F.F.: Choline acetyltransferase inhibitors. Configurational and electronic features of stryrlpyridine analogs. J. Medul. Chem. 12:134-138, 1969 .

Chao, L.P. and Wolfgram, F.: Activation, inhibition and aggregation of choline acetyltransferase (E.C. 2.3.1.6.). J. Neurochem. 23:697-701, 1974 .

Chao, L.P.: Subunits of choline acetyltransferase (E.C. 2.3. 1.6.). J. Neurochem. 25:261266, 1976 .

Chase, J.F.A. and Tubbs, P.K.: Specific inhibitors of carnitine acetyltransferase and other acetyltransferases. Biochem. J. 100:47-48, 1966.

Cleland, w.w.: The kinetics of enzyme-catalyzed reactions with two or substrates or products. Biochim. Biophys. Acta 67:104-137, 1963 .

Cohen, E.L. and Wurtman, R.S.: Brain acetylcholine:increase after systemic choline administration. Life Sci. 16: 1095-1102, 1975. 
Collier, B. and Katz, H.S.: The synthesis, turnover, and release of surplus acetylcholine in a sympathetic ganglion. J. Physiol. 214:537-552, 1971.

Collier, B., Poon, P. and Salehmoghaddam, S.: The formation of choline and of acetylcholine by brain in vitro.

J. Neurochem. 19:51-60, 1972 .

Collier, B. and Katz, H.S.: Acetylcholine synthesis from recaptured choline by a sympathetic ganglion. J. Physiol. $238: 639-645,1974$.

Collier, B., Lovat, S., Ilson, D., Barker, L.A. and Mittag, T.W.: The uptake, metabolism and release of homocholine: studies. with rat brain synaptosomes and cat superior cervical ganglion. J. Neurochem. 28:331-339, 1977.

Collier, B. and Ilson, D.: The effect of preganglionic nerve stimulation on the accumulation of certain analogues of choline by a sympathetic ganglion. J. Physiol. 264 : $489-498,1977$.

Cooper, J.R., Bloom, F.E. and Roth, R.H.: In The Biochemical Basis of Neuropharmacology. New York: Oxvord University Press, 1978.

Cornford, E.M., Braun, L.P., and Oldendorf, W.H.: Carrier mediated blood-brain barrier transport of choline and certain choline analogues. J. Neurochem. 30:299-308, 1978 .

Currier, S.F. and Mautner, H.G.: On the mechanism of action of choline acetyltransferase. Proc. Nat. Acad. Sci. USA $71: 3355-3358,1974$.

Crossland, J. and Slater, P.: "Effect of some drugs on "free" and "bound" acetylcholine content of rat brain. Brit. J. Pharmacol. 33:42-47, 1968 .

Dahlberg, L. and Schuberth, J.: Regulation of plasma choline by base exchange. J. Neurochem. 29:933-934, 1977.

Daikuhara, Y., Tsunemi, T. and Takeda, Y.: The role of ATP citrate lyase in the transfer of acetyl groups in rat liver. Biochem. Biophys. Acta 158:51-61, 1968 .

Davies, G.E. and Stark, G.R.: Use of dimethyl suberimidate, a cross-linking reagent, in studying the subunit structure of oligomeric proteins. Proc. Nat. Acad. Sci. USA $66: 651-656,1970$. 
Davis, K.L., Berger, P.A. and Hollister, L.E.: Choline for tardine dyskinesia. New England J. Med. 293, 1975.

Davis, K.L., Hollister, L.E., Brachas, J.D., and Berger, P.A.: Choline in tardine dyskinesia and Huntingdon's disease. Life Sci. 19:1507-1516, 1976.

Davis, J.M., Janowsky, D. and Casper, R.C.: In Neuroregulators and Psychiatric Disorders. New York: Oxford University Press, p 434, 1977.

Del Costello, J. and Katz, B.: La base 'quantale' de la transmission neuromusculaire. In Microphysiologie Comparee des Elements Excitables. Coll. Internat. C.N.R.S., Paris, No. 67, pp 245-258, 1957.

De Potter, W.P. and Chubb, I.W.: The turnover rate of noradrenergic vesicles. Biochem. J. 125:375-376, 1971.

De Robertis, E.D.P. and Bennett, H.S.: Submicroscopic vesicular component in the synapse. Fed. Proc. 13:35, 1954.

De Robertis, E.D.P. and Bennett, H.S.: SOme features of the submicroscopic morphology of synapses in frog and earth worm. J. Biophys. Biochem. Cytol. 1:47-58, 1955.

De Robertis, E., Rodriguez De Lores Arnaiz, G., Saliganicoff, L., Pellgrino, De Iraldi, A., and Zieher, L.M.: Isolation of synaptic vesicle and structural organization of the acetylcholine system within brain nerve endings. J. Neurochem. 10:225-235, 1963.

Diamond, I. and Kennedy, E.P.: Carrier mediated transport of choline into synaptic nerve endings. J. Biol. Chem. $244: 3258-3263$, 1969 .

Diamond, I. and Fishman, R.A. : Development of Nat-stimulated glucose oxidation in synaptosomes. J. Neurochem. 21: 1043-1050, 1973.

Diebler, M. and Morot-Gaudry, Y.: Biosynthesis of acetylcoenzyme $A$ in electric organ of Torpedo marmarota in relation to acetylcholine metabolism. Biochem. J. $166: 447-453,1977$.

Domino, E.F., Mohrman, M.E., Wilson, A.E. and Ilaarstad, B.B.: Acetylsecohemicholinium-3, a new choline acetyltransferase inhibitor useful in neuropharmacology studies. Neuropharmacol. 12:549-561, 1973.

Dowd, J.E. and Riggs, D.S.: A comparison of estimates of Michaelis-Menton kinetic constants from various linear transformations. J. Biol. Chem. 240:863-869, 1965. 
Dowdal1, M.J. and Simon, E.J.: Comparative studies on synaptosomes: uptake of $\left[\mathrm{N}-\mathrm{Ne}-3_{\mathrm{H}}\right]$ choline by synaptosomes from squid optic lobes. J. Neurochem. 21:969-982, 1973.

Dowdall, M.J. and Whittaker, V.P.: Comparative studies on synaptosome formation: the preparation of synaptosomes from the head ganglia of the squid, Ladigo pealii. J. Neurochem. 20:921-935, 1973.

Evans, C.A.N. and Saunders, N.R.: The distribution of acetylcholine in normal and in regenerating nerves. J. Physiol. $192: 79-92,1967$.

Fatt, P. and Katz, B.: Some observations on biological noise. Nature, 166:597-598, 1950.

Fatt, P. and Katz, B.: Spontaneous subthreshold activity at motor nerve endings. J. Physiol. 117:109-128, 1952.

Feigenson, M.E. and Barrnett, R.J.: Combined pharmacological and fine-structural studies of choline-o-acetyltransferase at the myoneural junction. Brain Res. 119:155$179,1977$.

Feldberg, W.: Present views on the mode of action of acetylcholine in the central nervous system. Physiol. Rev. $25: 596-642,1945$.

Fernandez-Moran, H.: Electron microscopy of nervous tissue. In Metabolism of the Nervous System, ed. Richter, P. London: Pergam, pp 1-34, 1957.

Fine, R.E. and Bray, D.: Actin in growing nerve cells. Nature 234 : 115-118, 1971 .

Fonnum, F.: A radiochemical method for the estimation of choline acetyltransferase. Biochem. J. 100:479-484, 1966.

Fonnum, F.: The "compartmentation" of choline acetyltransferase within the synaptosome. Biochem. J. 103:262$270,1967$.

Fonnum, F.: Choline acetyltransferase binding to and release from membranes. Biochem. J. 109:389-398, 1968.

Fonnum, F.: Isolation of choline esters from aqueous solutions by extraction with sodium tetraphenylboron in organic solvents. Biochem. J. 113:291-298, 1969.

Fonnum, F.: Surface charge of choline acetyltransferase from different species. J. Neurochem. 17:1095-1100, 1970. 
Fonnum, F. and Malthe-Sorensson, D.: Molecular properties of choline acetyltransferase and their importance for the compartmentation of acetyletholine synthesis: Progr. Brain Res. 36:13-27, 1972.

Fonnum, F.: Recent development in biochemical investigation of cholinergic transmission. Brain Res. 62:497-507, 1973.

Fonnum, F.: In Cholinergic Mechanisms, ed. Waser, P.F., New York: Raven Press, 1975.

Freeman, J.J., Choi, R.L., and Jenden, D.J.: Plasma choline: Its turnover and exchange with brain choline. J. Neurochem. 24:729-734, 1975 .

Freeman, J.J. and Jenden, D.J.: The source of choline for acetylcholine synthesis in brain. Life Sci. 19:949$956,1976$.

Friend, D.S. and Farquhar, N.G.: Functions of coated vesicles during protein absorption in the rat vas deferens. J. Cell Biol. 161:259-268, 1967.

Gardiner, J.E.: The inhibition of acetylcholine synthesis by hemicholinium. Biochem. J. 81:297-303, 1961.

Gibson, G.F. and Blass, J.P.: Impaired synthesis of acetylcholine in brain accompanying mild hypoxia and hypoglycemia. J. Neurochem. 27:37-42, 1976.

Glick, S.D. Mittag, T.W. and Green, J.P.: Central cholinergic correlates of impaired learning. Neuropharmacol. $12: 291-296,1973$.

Glover, V.A.S. and Potter, L.T.: Purification and properties of choline acetyltransferase from ox brain striate nuclei. J. Neurochem. 18:571-580, 1971 .

Goldberg, M.E., Salama, A.I. and Blum, S.W.: Inhibition of choline acetyltransferase and hexobarbitone metabolizing enzymes by naphthyl vinyl pyridine analogues. J. Pharm. Pharmacol. 23:384-385, 1971 .

Goldman, R., Kedem, O. and Katcholski, F.: Kinctic bchavior of alkaline phosphatose colloidon membranes. Biochemistry 10:165-172, 1971.

Goldstein, L., Levin, Y., and Katchalski, E.: A water-insoluble polyanionic derivative of trypsin II. Effect of the polyelectrolyte carrier on the kinetic behavior of the bound trypsin. Biochemistry 3:1913-1919, 1964 . 
Gray, E.G. and Whittaker, V.P.: The isolation of nerve endings from brain: an electron microscopic study of cell fragments derived by homogenization and centrifugation. J. Anat. 96:79-87, 1962 .

Gray, E.G.: Electron microscopy of presynaptic organelles of the spinal cord. J. Anat. 97:101-106, 1963.

Gray, E.G.: Problems of interpreting the fine structure of vertebrae and invertebrae synapses. Int. Rev. Gen. Exp. Zool. 2:139-170, 1966.

Gray, E.G.: Are coated vesicles artifacts? J. Neurocytol. $1: 363-382,1972$.

Gray, E.G.: The cytonet, plain and coated vesicles, reticulosomes, multivesicular bodies and nuclear pores. Brain Res. 62:329-336, 1973.

Guyenet, P., Lefresne, P., Rossier, J., Beaujouan, J. and Glowinski, J.: Effect of sodium, hemicholinium-3- and antiparkinson drugs on ${ }^{14} \mathrm{C}$ acetylcholine synthesis and $3 \mathrm{H}$ choline uptake in rat striatal synaptosomes. Brain Res. 62:523-529, 1973 .

Haga, T. and Noda, H.: Choline uptake systems of rat brain syncoptosomes. Biochem. Biophys. Acta 291:564-575, 1973.

Harris, L.W., Hegl, W.C., Stitcher, D.L., and Moore, R.D.: Effect of atropine and/or physostigmine on cerebral acetylcholine in rats poisoned with Soman. Iife Sci. 22:907-910, 1978 .

Hattori, T., Singh, V.K., McGeer, E.G., and McGeer, P.L.: Immuno-histochemical localization of choline acetyltransferase containing neurons and their relationship with dopaminergic synapses. Brain Res. 120:164-173, 1976 .

Haubrich, D.R., Wang, P.F.L. and Clody, D.E.: Increase in tissue concentration of acetylcholine in guinea pigs in vivo induced by administration of choline. Life Sci. 14:921-927, 1974 .

Haubrich, D.R., Wang, P.F.L. and Wedcking, P.W.: Distribution and metabolism of intravenously administered choline [methyl-3H] and synthesis in vivo of acetylcholine in various tissue of guinea pigs. J. Pharmacol. $193: 246-255,1975$.

Haubrich, D.R. and Chippendale, T.J.: Regulation of acetylcholine synthesis in nervous tissue. Life Sci. 20: $1465-1478,1977$. 
Hebb, C.O., Krnjevic, K. and Silver, A.: Acetylcholine and choline acetyltransferase in the diaphragm of the rat. J. Physiol. 171:504-513, 1964 .

Hebb, C.: Biosynthesis of acetylcholine in nervous tissue. Physiol. Rev. 52:918-957, 1972.

Hebb-, C., Mann, S.P. and Mead, J.: Measurement and activation of choline acetyltransferase. Biochem. Pharmacol. 24:1007-1011, 1975 .

Hemsworth, B.A. and Smith, J.C.: The enzymic acetylation of choline analogues. J. Neurochem. 17:171-177, 1970.

Henderson, G.I. and Sastry, B.V.R.: Kinetic studies of the reaction mechanism of human placental choline acetyltransferase. Fed. Proc. 30:621, 1971 .

Heusen, J.E. and Reese, T.S.: Evidence for recycling of synaptic vesicle membrane during transmitter release at the frog neuromuscular junction. J. Cell Biol. 57: $315-344,1973$.

Hodgkin, A.L. and Martin, K.: Choline uptake by giant axons of Loligo. J. Physiol. 179:26-27, 1965.

Holtzman, E., Novikoff, A.B. and Villaverde, H.: Lysosomes and GERL in normal and chromatolytic neurons of the rat ganglion nodosum. J. Cell Biol. 33:419-435, 1967.

Harnby, W.E., Lilly, M.D. and Crook, E.M.: Some changes in the reactivity of enzymes resulting from their chemical attachment to water-insoluble derivatives of cellulose. Biochem. J. 107:669-674, 1968.

Heroh, L.B.: Re-evaluation of the kinetic mechanism of the choline acetyltransferase reaction. Fed. Proc. 36: 633,1977 .

Hochstadt, J. and Quinlan, D.: The function and activity of certain membrane enzymes when localized on and off membrane. J. Cell physiol. 89:839-852, 1976.

Illingworth, D.R. and Portman, D.W.: The uptake and metabolism of plasma lysophosphatidylcholine in vivo by the brain of squirrel monkeys. Biochem. J. 130:557-560, 1972 .

Ilson, D. and Collier, B.: Triethylcholine as a precursor to a false transmitter. Nature 254:618-620, 1975 .

Ilson, D., Collier, B. and Boska, P.: Acetyltriethylcholine: A cholinergic false transmitter in cat superior cervical ganglion and rat cerebral cortex. J. Neurochem. 28: $371-381,1977$. 
Jenden, D.J., Choi, L., Silverman, R.W., Steinborn, J.A., Roch, M. and Booth, R.A.: Acetylcholine turnover estimation in brain by gas chromatography/mass spectrometry. Life Sci. 14:55-61, 1974 .

Jenden, D.J., Jope, R.S. and Weiler, M.H.: Regulation of acetylcholine synthesis. Does cytoplasmic acetylcholine control high affinity choline uptake? Science $194: 635-637,1976$.

Jones, D.G.: The morphology of the contact region of vertebrae synaptosomes. Z. Zellfousch. 95:263-279, 1969.

Jones, D.G.: A study of the presynaptic network of Octupus synaptosomes. Brain Res. 20:145-158, 1970.

Jones, D.G. and Bradford, H.F.: The relationship between complex vesicles, dense-cored vesicles and dense projection in cortical synaptosomes. Tissue and Cell 3:177190,1971 .

Jones, D.G.: On the ultrastructure of the synapse: The synaptosomes as a morphological tool. In The structure and Function of Nervous Tissue, ed. Bourne, G.H., Vol. 6, New York: Academic Press, pp 81-129, 1972.

Jones, D.G.: In Synapses and Synaptosomes: Morphological Aspects, London: Chapman and Hall, 1975.

Jones, D.G.: Morphological features of central synapses with emphasis on the presynaptic terminal. Life Sci. 21: $477-492$, 1977 .

Jope, R.S. and Jenden, D.J.: Synaptosomal transport and acetylation of choline. Life Sci. 20:1389-1392, 1977.

Jope, R.S., Weiler, M.H. and Jenden, D.J.: Regulation of acetylcholine synthesis: control of choline transport and acetylation in synaptosomes. J. Neurochem. 30: 949-954, 1978 .

Kadota, K. and Kadota, T.: A nucleoside diphosphate phosphohydrolase present in coated-vesicle fraction from synaptosomes of guinea pig whole brain. Brain Res. 56: $371-376,1973$.

Kaita, A.A. and Goldberg, A.M.: Control of acetylcholine synthesis-the inhibition of choline acetyltransferase by acetylcholine. J. Neurochem. 16:1185-1191, 1969.

Kanaseki, T. and Kadota, K.: The 'vesicle in a basket.' A morphological study of the coated vesicle isolated from the nerve endings of the guinea pig brain, with special reference to the mechanism of membrane movements. J. Cell Biol. 42:202-220, 1969 . 
Karlsson, J.O. and Sjostrand, J.: Synthesis, migration and turnover of protein in retinal ganglion cells. J. Neurochem. 18:749-767, 1971 .

Kasa, P., Mann, S.P. and Hebb, C.: Localization of choline acetyltransferase. Ultrastructural localization in spinal neurons. Nature 226:814-816, 1970.

Kasa, P.: Ultrastructural localization of choline acetyltransferase and acetylcholinesterose in central and peripheral nervous tissue. Progr. Brain Res. 34:337344,1971 .

Katz, B. and Miledi, R.: A study of spontaneous miniature potentials in spinal motoneurons. J. Physiol. 168: $389-422$, 1963.

Katz, B.: In Nerve, Muscle and Synapse. New York: McGrawHill, $19 \overline{66 .}$

Katz, B.: In The Release of Neural Transmitter Substance. Liverpool: Liverpool University Press, 1969.

Katz, M.S., Salenoghaddam, S. and Collier, B.: The accumulation of radioactive acetylcholine by a sympathetic ganglion and by brain failure to label endogenous stores. J. Neurochem. 20:569-579, 1973 .

Krell, R.D. and Goldberg, A.M.: Effect of choline acety1transferase inhibitors on mouse and guinea pig brain choline and acetylcholine. Biochem. Pharmacol. 24:391$396,1975$.

Krnjevic, K. and Miledi, R.: Acetylcholine in mammalian neuromuscular transmission. Nature 182:805-806, 1958.

Krnjeciv,. K., Pumain, P. and Renaud, L.: The mechanism of excitation by acetylcholine in the cerebral cortex. J. Physiol. 215:247-268, 1971.

Kucenski, R., Segal, D.S. and Mandell, A.J.: Regional and subcellular distribution and kinetic properties of rat brain choline acetyltransferase - some functional considerations. J. Neurochem. 24:39-45, 1975 .

Kuhar, M.J., Sethy, V.II., Roth, R. and Aghajanian, G.K.: Choline selective accumulation by central cholinergic neurons. J. Neurochem. 20:581-593, 1973.

Kuhar, M.J., DeHaven, R.N., Yamamora, H.I., Rommelspracher,H. and Simon, J.H.: Further evidence for cholinergic hakenolo-interpeduncular neurons:pharmacologic and functional characteristics. Brain Res. 97:265-275, 1975. 
Kuhar, M.J. and Murrin, L.C.: Sodium dependent, high af- finity choline uptake. J. Neurochem. 30:15-21, 1978.

Kuhar, M.J. and Zarbin, M.A.: Synaptosomal transport: a chloride dependence for choline, GABA, glycine and several other compounds. J. Neurochem. 31:251-256, 1978.

Kuriyama, K., Roberts, E. and Vos, J.: Some characteristics of binding of gamma-aminobutyric acid and acetylcholine to synaptic vesicle fractions from mouse brain. Brain Res. $9: 231-252$, 1968 .

Lai, J.C.K., Walsh, J.M., Dennis, S.C. and Clark, J.B.: Synaptic and non-synaptic mitochondria from rat brain: isolation and characterization. J. Neurochem. 28:625$634,1977$.

Lentner, N.: In Introduction to Applied Statistics. Boston: Prindle, Weber and Schmidt, Inc., 1975.

Lowry, O.H., Rosebrough; N.J., Farr, A.L. and Randall, R.J.: Protein measurement with the Folin phenol reagent.

J. Biol. Chem. 193:265-275, 1951 .

MacIntosh, F.C.: The distribution of acetylcholine in the peripheral and the central nervous system. J. Physiol. $99: 436-442$, 1941 .

MacIntosh, F.C.: Acetylcholine. In Basic Neurochemistry, eds. Siegel, G.C., Albers, R.W., Katzman, R. and Agranoff, B.W. Boston: Little, Brown and Company, 1976.

Malthe-Sorensson, D., Anderson, R.A. and Fonnum, F.: Biochemical and pharmacological properties of acryloylcholine, an inhibitor of choline acetyltransferase. Biochem. Pharmacol. 23:577-586, 1974 .

Malthe-Sorensson, D.: Choline acetyltransferase-evidence for acetyl transfer by a histidine residue. J. Neurochem. 27:873-881, 1976 .

Mann, S.P. and Ilebb, L.: Free choline in the brain of the rat. J. Neurochem. 28:241-244, 1977 .

Mannervik, B. and Sorbo, B.: Inhibition of choline acetyltransfcrasc from bovine cauclate nuclcus by sulfhydryl reagents and reactivation of the inhibited enzyme. Biochem. Pharmacol. 19:2509-2516, 1970.

Marchbanks, R.M.: Exchangcability of radioactive acetylcholine with bound acetylcholine of synaptosomes and synaptic vesicles. Bioch dm. J. 106:87-95, 1968. 
Marchbanks, R.M.: In Handbook of Psychopharmacology, 3 , eds. Iversen, L. L., Iversen, S.D. and Synder, S. $\bar{H}$. New York: Plenum Press, pp 247-325, 1975.

McCamen, R.E. and Hunt, J.M.: Microdetermination of choline acetylase in nervous tissue. J. Neurochem. 12:253259,1965 .

McCamen, R.E., Rodriguez de Lores Arnaiz, G. and De Robertis, E.: Species differences in subcellular distribution of choline acetylase, acetylcholinesterase, 5-hydroxytryptophan decarboxylase, and monoamine oxidase in four species. J. Neurochem. 12:927-935, 1965.

Molenaar, P.C., Polak, R.L. and Nickolson, V.J.: Subcellular localization of newly formed $3_{\mathrm{H}}$ acetylcholine in rat cerebral cortex in vitro. J. Neurochem. 21:667-678, 1973.

Molenaar, P.C. and Polak, P.L.: Newly formed acetylcholine in synaptic vesicles in brain tissue. Brain Res. 62: $537-542,1973$.

Morris, D.: The choline acetyltransferase of human placenta. Biochem. J. 98:754-762, 1966 .

Morris, D. and Grewaal, D.S.: Halogen substituted derivatives of acetylcholine as inhibitors of choline acetyltransferase. Life Sci. 8, II:511-516, 1969.

Morris, D. and Grewaal, D.S.: Human placental choline acetyltransferase. Radiometric assay, inhibition by analogues of choline and isotopic exchange between choline and acetylcholine. European J. Biochem. 22:563-572, 1971.

Morris, D. and Hebb, C.: The, kinetic properties of human placental choline acetyltransferase. Biochem. J. 121: $20-21,1970$.

Morris, D., Maneckjec, A. and Hebb, C.: The kinetic properties of human placental choline acetyltransferase. Biochem. J. 125:857-863, 1971 .

Moss, B. and Rosenblum, E.N.: Hydroxylapatite chromatography of protein-sodium dodecyl sulfate complexes. J. Biol. Chem. 247:5194-5198, 1972 .

Nachmansohn, D. and Machado, A.L.: The formation of acetylcholine. A new enzyme choline acetylase. J. Neurophysiol. 6:397-403, 1943 .

Neidle, A., Van der Berg, C.J., and Grynbaum, A.: 'The heterogeneity of rat brain mitochondria isolated on continuous sucrose gradients. J. Neúrochem. 16:225-234, 1969. 
Oesch, F.: Trans-synaptic induction of choline acetyltransferase in the preganglionic neuron of the peripheral sympathetic nervous system. J. Pharmacol. Exp. Ther. $188: 439-446,1974$.

Patel, M.S. and Owen, O.E.: Lipogenesis from ketone bodies in rat brain: evidence for conversion of acetoacetate into acetyl-coenzyme $\mathrm{A}$ in the cytosol. Biochem. J. $156: 603-607,1976$.

Persson, B.O., Larsson, I., Schuberth, J. and Sorbo, B.: 3-bromoacetonyl trimethylammonium bromide, a choline acetylase inhibitor. Acta Chem. Scand. 21:2283-2284, 1967.

Polak, R.L. and Meeuws, M.M.: The influence of atropine on the release and uptake of acetylcholine by the isolated cerebral cortex of the rat. Biochem. Pharmacol. 15: $989-992,1966$.

Polak, R.I., Molenaar, P.C. and Van Gelder; M.: Acetyl choline metabolism and choline uptake in cortical slices. J. Neurochem. 29:477-485, 1977.

Potter, I.T., Glover, V.A.S. and Saelens, J.K.: Choline acetyltransferase from rat brain. J. Biol. Chem. $243: 3864-3870,1968$.

Potter, L.T.: In The Interaction of Drugs and Subcellular Components in Animal Cells, ed. Campbell, P.N. London: Churchill, pp 293-304, 1968.

Potter, L.T.: Synthesis, storage and release of ${ }^{14} \mathrm{C}$ acetylcholine in isolated rat diaphragm muscles. J. Physiol. 206 : 145-166, 1970 .

Puszkin, S. and Berl, S.: Actomyosin-like protein from brain. Separation and characterization of the actin like component. Biochim. Biophys. Acta 256:695-709, 1972 .

Pysh, J.J. and Wiley, R.G.: Synaptic vesicle depletion and recovery in cat sympathetic ganglia electrically stimulated in vivo. Evidence for transmitter secretion by exocytosis. J. Cell Biol. 60:365-374, 1974.

Richter, J.A. and Marchbanks, R.M.: Isolation of ${ }^{3} \mathrm{H}$ acetylcholine pools by subcellular fractionation of cerebral cortex slices incubated with $3_{\mathrm{H}}$ choline. J. Neurochem. $18: 705-712,1971$.

Robertson, J.D.: The ultrastructure of a reptilian myoneural junction. J. Biophys. Biochem. Cytol. 2:381-394, 1.956. 
Roskowski, R., Jr.: Acceleration of choline uptake after depolarization-induced acetylcholine release in rat cortical synaptosomes. J. Neurochem. 30:1357-1361, 1978.

Ross, L.L., Andreoli, V.M. and Marchbanks, R.M.: A morphological and biochemical study of subcellular fractions of the guinea pig spinal cord. Brain Res. 25:103-119, 1971 .

Rossier, J., Spantidakis, Y. and Benda, P.: The effect of $\mathrm{Cl}^{-}$on choline acetyltransferase kinetic parameters and a proposed role for $\mathrm{Cl}^{-}$in the regulation of acetylcholine synthesis. J. Neurochem. 29:1007-1012, $1977 \mathrm{a}$.

Rossier, J.: Acetyl-coenzyme A and coenzyme A analogues. Biochem. J. 165:321-326, 1977h.

Roth, T.F. and Porter, K.R.: Yolk protein uptake in the oocyte of the mosquito Aedes aegypti L. J. Cell. Biol. 20:313-32, 1964 .

Sacchi, O., Consolo, S., Peri, G., Prigioni, I., Ladinsky, H. and Puri, V.: Storage and release of acetylcholine in the isolated superior cervical ganglion of the rat. Brain Res. 151:443-456, 1978.

Saelens, J.K., Simke, J.P., Allen, M.P., and Conroy, C.A.: Some of the dynamics of choline and acetylcholine metabolism in rat brain. Arch. Int. Pharmacodyn. Ther. 203:305-312, 1973.

Salehmaghaddam, S.H. and Collier, B.: The relationship between acetylcholine release from brain slices and acetylcholine content of subcellular fractions prepared from brain.' J. Neurochem. 27:71-76, 1976.

Sastry, B.V.R., Olubadewo, J., Harbison, R.D. and Schmidt, D.E.: Human placental cholinergic system. Occurrence, distribution and variation with gestational age of acetylcholine in human placenta. Biochem. Pharmacol. 25:425-431, 1976 .

Schafer, R.: Acetylcholine:fast oxoplasmic transport in insect chemoreceptor fibers. Science 180:315-316, 1973 .

Schuberth, J., sparf, B., and sundwall, $\lambda_{.}$: on the turnover of acetylcholine in nerve endings of moose brain in vivo. J. Neuro. Chem. 17:461-468, 1970 . 
Simon, J.R. and Kuhar, M.J.: Impulse-flow regulation of high affinity choline uptake in brain cholinergic nerve terminals. Nature 255:162-163, 1975.

Simon, J.R., Atweh, S., and Kuhar, M.J.: Sodium dependent high affinity choline uptake: a regulatory step in the synthesis of acetylcholine. J. Neurochem. $26: 908-915,1976$.

Sing,. V.K., McGeer, E.G. and McGeer, P.L.: Two immunologically different choline acetyltransferase in human striatum. Brain Res. 96:187-191, 1975a.

Singh, V.K., McGeer, E.G. and McGeer, P.L.: Acetylcholine inhibition of two different forms of choline acetyltransferase. 5th Ann. Soc. Neurosci. 2:384, 1975b.

Smith, J.C., Cavallito, C.J. and Foldes, F.F.: Choline acetyltransferase inhibitors: a group of styrylpyridine analogs. Biochem. Pharmacol. 16:2438-2441, $1967 /$

Sollenberg, J. and Sorbo, B.: On the origin of the acetyl moiety of acetylcholine in brain: studies with a differential labelling technique using a ${ }^{3} \mathrm{H}-1{ }^{4} \mathrm{C}$ mixed labelled glucose and acetate. J. Neurochem. $17: 201-207,1970$.

Sparf, B.: On the turnover of acetylcholine in brain. Acta Physiol. Scand. 397:101, 1973.

Speth, R.C., Schmidt, D.E., Rama Sastry, B.V. and Buxbaum, D.M.: In vivo and in vitro effects of bromoacetylcholine on rat brain acetylcholine levels and choline acetyltransferase activity. Neuropharmacol. $15: 287-290,1976$.

Spyker, J.M., Sparber, S.B. and Goldberg, A.M.: Subtle consequences of methyl-mercury exposure:behavioral deviation in offspring of treated mothers. Science $177: 621-623,1972$.

Stavinoha, W.B. and Weintraub, S.T.: Choline content of rat brain. Science 183:964-965, 1974 .

Stephenson, M. and Rowatt, E.: The production of acetylcholine by a strain of Lactobacillus plantarum.

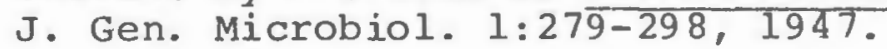

Sterling, G.H. and O'Neill, J.J.: Citrate as the precursor of the acetyl moiety of acetylcholine. J. Neurochem. $31: 525-530,1978$. 
Strist, P., Akert, K., Sandri, C., Livingston, R.B. and Moore, H.: Dynamic ultrastructure of presynaptic membranes at nerve terminals in the spinal cord of rats. Anestheszied and unanesthesized preparations compared. Brain Res. 48:11-26, 1972.

Suszkiw, J.B.: Acetylcholine,translocation in synaptic vesicle ghosts in vitro. J. Neurochem. 27:853-857, 1976 .

Suszkiw, J.B. and Pilar, G.: Selective localization of a high affinity choline uptake system and its role in Ach formation in cholinergic nerve terminals. J. Neurochem. 26:1133-1138, 1976.

Takeno, K., Nishie, A. and Yanagiya, I.: Bound acetylcholine in the nerve ending particles. J. Neurochem. $16: 47-52,1969$.

Tobias, J.M., Lipton, M.A. and Lepinat, A.A.: Effect of anesthetics and convulsants on brain acetylcholine content. Proc. Soc. Exp. Biol. Med. 61:51-54, 1946.

Tucek, S.: On the question of the localization of choline acetyltransferase in synaptic vesicles. J. Neuro. Chem. 13:1329-1332, 1966.

Tucek, S.: Subcellular distribution of acetyl CoA synthetase, ATP citrate lyase, citrate synthetase, choline acetyltransferase, fumarate hydratase and lactate dehydrogenase in mammalian bra.in tissue. J. Neuro chem. 14:531-545, 1967.

Tucek, S. and Cheng, S.C.: Precursors of acetyl groups in acetylcholine in the brain in vivo. Biochem. Biophys. Acta 208:538-540, 1970 .

Van der Berg, C.I.: In Metabolic Compartmentation in the Brain, eds. Balzas, R. and Cremer, J.E. London: MacMillan, pp 137-166, 1973.

Weber, K. and Osborn, M.: The reliability of molecular weight determinations by dodecyl sulfate-polyacrylamide gel elcctrophoresis. J. Biol. Chem. 244: $4406-4412$, 1969 .

Weil, D.E., Busby, W.H. and McIlwain, D.L.: Choline acetyltransferase activity in large ventral spinal neurons. J. Neurochem. 29:847-852, 1977.

Welsch, F.: The cholinergic system in tissues without innervation. Choline acetyltransferase, choline and acetylcholine in the placenta of the rhesus monkey (Macaca molatta). Biochem. Pharmacol. 26:1281-1286, $1 \overline{977 .}$ 
White, II.L. and Cavallito, C.J.: Choline acetyltransferase. Enzyme mechanism and mode of inhibition by styrylpyridine analogues. Biochim. Biophys. Acta $206: 343-358,1970$.

White, H.L. and Wu, J.C.: Kinetics of choline acetyltransferases (E.C. 2.3.1.6.) from women and other mammalian central and peripheral nervous tissues. J. Neurochem. 20:297-307, 1973.

Whittaker, V.P.: The isolation and characterization of acetylcholine-containing particles from brain. Biochem. J. 72:694-706, 1959 .

Whittaker, V.P.: The vesicle hypothesis. In Excitatory Synaptic Mechanisms, eds. Andersen, P. and Jensen, J.K.S. Oslo:Universitatsforlaget, pp 67-76, 1970 .

Whittaker, V.P., Michaelson, I.A. and Kirkland, R.J.A.: The separation of synaptic vesicles from nerve ending particles (synaptosomes). Biochem. J.90: $293-303,1964$.

Whittaker, V.P. and Sheridan, M.N.: The morphology and acetylcholine content of isolated cerebral cortical synaptic vesicles. J. Neurochem. 12:363-372, 1965.

Yamamura, H.I. and Synder, S.H.: Choline: High affinity ptake by rat brain synaptosomes. Science 178:626628,1972 .

Yamamura, H.I. and Synder, S.H.: High affinity transport of choline into synaptosomes of rat brain. J. Neurochem. 21:1355-1374, 1973 . 